\title{
LAS PLANTAS EN LA ALIMENTACIÓN DE POBLADORES RURALES DE LOS AMBIENTES SERRANOS DE LA CALERA (DPTO. COLÓN, CÓRDOBA, ARGENTINA). UNA PERSPECTIVA ETNOBOTÁNICA DIACRÓNICA
}

\author{
Plants in the diet of rural inhabitants of the mountain surroundings of La Calera (Department \\ of Colón, Córdoba, Argentina). A diachronic ethonbotanical perspective
}

ALEJANDRO FERNÁNDEZ1 \& GUSTAVO J. MARTÍNEZ[1 1

\begin{abstract}
Resumen: El trabajo propone caracterizar el rol de las plantas alimenticias en pobladores rurales campesinos de los ambientes serranos de una localidad de las Sierras Chicas de Córdoba. En lo metodológico se siguió un proceso de investigación y de obtención de datos etnobotánicos a campo, combinando metodologías de las ciencias sociales y naturales y recurriendo a la complementariedad de los análisis cualitativos y cuantitativos. Se aplicaron encuestas semiestructuradas en 30 unidades domésticas y 14 entrevistas en profundidad. Se documentaron 36 especies y 42 aplicaciones alimenticias diferentes, sin incluir las hortalizas y verduras de cultivo; así como 121 preparados alimenticios tradicionales y actuales. Una gran cantidad de prácticas culinarias, recetas y platos tradicionales compilados en este trabajo coinciden con el inventario de mediados del siglo pasado para el folklore de la comida cordobesa. En lo que concierne al cambio en materia de alimentación, se visibilizan particularmente las razones socioculturales relacionadas a transformaciones en el estilo de vida, antes que motivos ambientales. Finalmente se observan recetarios cada vez menos diversificados, pérdida de ingredientes y del uso de cultígenos tradicionales en la culinaria doméstica.
\end{abstract}

Palabras clave: Alimentación, diacrónica, etnobotánica, plantas comestibles, ruralidad.

Summary: The work aims at characterizing the role played by food plants in the diet of rural peasants living in the mountain surroundings of Sierras Chicas, province of Córdoba. Methodologically, a process of research and obtaining ethnobotanical data in the field was followed, combining methods from the social and natural sciences and conducting complementarity qualitative and quantitative analyses. Semi-structured surveys were administered in 30 domestic units and 14 in-depth interviews were done. A total of 36 species and 42 different food applications were registered, excluding garden produce and farming vegetables; in addition to 121 present-day and traditional food preparations. A large number of culinary practices, recipes and traditional dishes compiled in this work coincide with the inventory dating back to the middle of the last century for the folklore of Cordoba's food. In relation to food change, socio-cultural reasons related to lifestyle changes, rather than environmental reasons, were particularly visible. Finally, we found recipes increasingly less diversified, loss of ingredients and the use of traditional cultigens in domestic cooking.

Key words: Diachronic, edible plants, ethnobotany, food, rurality.

\footnotetext{
${ }^{1}$ Instituto de Antropología de Córdoba (IDACOR - CONICET) y Museo de Antropología (FFYH - UNC). Hipólito Yrigoyen 174. Córdoba. E-mail: gustmart@yahoo.com
} 


\section{Introducción}

Uno de los tópicos más robustos y ampliamente estudiados de la etnobotánica es el de la alimentación y las especies comestibles, el cual reviste múltiples aristas y presenta estrecha vinculación con otras disciplinas científicas. En América del Sur los estudios etnobotánicos vinculados a la alimentación adquieren una particular relevancia, debido al alto porcentaje de especies endémicas que se hallan presionadas por los procesos de degradación ambiental (Scarpa, 2009).

La documentación de especies y usos alimenticios varía en las diferentes regiones de Argentina, quedando aún muchos espacios por explorar. En la provincia de Córdoba el trabajo de Arias Toledo et al. (2007a, b) registraron entre 15 y 25 especies silvestres para dos áreas fitogeográficamente diferentes (Chaco Árido y Chaco Serrano respectivamente), mientras que Toledo et al. (2015) compilaron 34 frutos comestibles para la provincia, y Saur Palmieri et al. (2018) refirieron específicamente 20 frutos para la región del Cerro Colorado también en la región del Chaco Serrano. También aparecen estos temas como parte de trabajos de etnobotánica general de pobladores criollos para la región del Chaco Árido de Córdoba (Trillo et al., 2014; Trillo, 2016). En el caso de poblaciones campesinas y aborígenes del norte y sur de Argentina, existen otros trabajos que no citaremos, dado que incluyen otros complejos bioculturales y geográficos diferentes a los de la provincia de Córdoba.

Entre los temas habitualmente tratados encontramos las formas de aprovisionamiento y recolección, formas de preparación, conservación de plantas comestibles, los colorantes y condimentos, los tipos de comidas y preparados, los implementos y la cultura material culinaria, la cocina y comensalidad ${ }^{2}$,

\footnotetext{
${ }^{2}$ Aguirre (2007) al referirse a la comensalidad, da cuenta de que "la mesa familiar o la comida institucional en un comedor pueden estar compuestas por el mismo menú, pero la situación social (en este caso privada o pública) y su significación para la vida de las personas cambia radicalmente el evento alimentario porque el momento de compartir la comida es un momento privilegiado de la reproducción física y social de los individuos y los grupos"
}

entre otros, (Scarpa 2012). Concurren en este ámbito de la subsistencia diferentes abordajes teóricos, tales como los estudios folklóricos -señalaremos como ejemplo los trabajos de Grimaut (2011, 2012) para Córdoba-, y, aunque para otras regiones y grupos culturales los enfoques diacrónicos, que dan cuenta de las transformaciones culturales en materia de alimentación (Arenas, 2003; Martínez, 2012; Scarpa \& Pacor, 2017). Asimismo en los últimos años, el rol de las plantas autóctonas comestibles en la alimentación ha adquirido notoriedad en el discurso y prácticas sociales de organizaciones no gubernamentales y estatales, toda vez que éstas se vinculan con tópicos como la nutrición, la soberanía y seguridad alimentaria ${ }^{3}$, las estrategias de consumo, las gastropolíticas, por citar algunas de las aproximaciones teóricas. Éstos, y otros temas, han motivado el interés de estudios de antropología y sociología de la alimentación, de los que destacaremos para nuestro país los trabajos de Aguirre (2004) y Alvarez \& Pinotti (1997, 2000), todos ellos de valor para discutir la labor etnobotánica que aquí se propone.

El presente trabajo tiene como objetivo caracterizar desde la perspectiva de la etnobotánica el rol de las plantas alimenticias en pobladores rurales de los ambientes serranos de localidad de La Calera (Dpto. Colón, Córdoba, Argentina). Asimismo nos proponemos analizar el contexto cultural de la alimentación en el que tiene lugar el uso de estas plantas, en particular los rasgos de la comensalidad. Se propone para ello: documentar la identidad botánica, los conocimientos y los usos de las especies vegetales alimenticias describiendo las características, propiedades y aplicaciones de cada una de ellas en el marco cultural de los pobladores locales; caracterizar la relevancia e importancia cultural de las especies alimenticias, identificando categorías locales de clasificación u otros criterios

\footnotetext{
3 Según la Organización de las Naciones Unidas para la Agricultura y la Alimentación (FAO, 1996), "la seguridad alimentaria existe cuando todas las personas tienen acceso en todo momento (ya sea físico, social y económico) a alimentos suficientes, seguros y nutritivos para cubrir sus necesidades nutricionales y las preferencias culturales para una vida sana y activa".
} 
de referencia; e identificar factores que influencian la provisión y aprovechamiento de los recursos comestibles en los ámbitos y población de estudio, interpretándolos, en perspectiva diacrónica, en el marco de las transformaciones culturales y ambientales locales. El trabajo reviste interés en tanto se trata de una zona en la que existe un reducido grupo de pobladores criollos campesinos coexistiendo con población neorrural y urbana, abarca también el contexto de un área protegida perteneciente a La Calera (Reserva Hídrica Natural y Recreativa Bamba), razón por la que sus resultados pueden ser relevantes para la conservación biocultural y ambiental.

\section{Materiales y Métodos}

\section{Área y población de estudio}

La localidad de La Calera posee una extensión de $128 \mathrm{~km}^{2}$, pertenece al departamento Colón, y colinda con la ciudad de Córdoba por su lado oeste conformando el gran Córdoba junto con otras localidades. En las últimas décadas registra un gran aumento poblacional con 31.992 habitantes aproximadamente (Censo Provincial de Población, 2010). Se encuentra emplazada en el sector en que se unen el piedemonte oriental de las Sierras Chicas con la llanura pampeana.

Desde el punto de vista fitogeográfico pertenece su mayor parte al Distrito del Chaco Serrano de la Provincia Chaqueña según Cabrera (1994), formando parte de la ecoregión del Chaco Seco según el criterio de Torrella \& Adámoli (2005). En general, el bosque serrano está dominado por Schinopsis lorentzii (orco-quebracho), junto con Lithraea molleoides (molle de beber) y Zanthoxylum coco (coco) especialmente en el sur, y por gran cantidad de cactáceas y fabáceas espinosas en el norte (Giorgis et al., 2011).

La Calera debe su nombre a los yacimientos de piedra caliza, los cuales fueron explotados desde los inicios de la localidad hasta el presente. Otra actividad en pleno auge y que plantea problemáticas nuevas a la región es el inmobiliario, siendo la localidad con más barrios cerrados de Córdoba, 11 de 40. Este crecimiento urbano carece de una adecuada planificación del territorio, y sumado a esto, también posee el mayor porcentaje de hogares con alguna necesidad básica insatisfecha, entre las grandes ciudades de Córdoba. Así, queda en evidencia el contraste entre sus habitantes, existiendo barrios antiguos que todavía carecen de agua y/o gas, incluso de escrituras, lo que ha ocasionado problemáticas de tierras y desalojos, hasta los modernos barrios privados con importantes instalaciones. Otra actividad importante es el turismo, ésta fue una de las primeras villas veraniegas de la provincia y hoy busca reactivar este sector con la revalorización de su patrimonio cultural. En relación con la historia poblacional estuvo vinculada al trabajo de la cal y la piedra, y su población criolla dedicada a la cría de ganado, presenta la posesión veinteañal de territorios en algunos casos cedidos por empresarios de Estancia Minetti. Al presente el territorio disponible para la cría de animales ha quedado muy disminuido, obligando a los campesinos en gran parte de los casos a deshacerse de los mismos.

Cabe notar que desde el punto de vista ambiental este y otro tipos de estudios sobre vegetación resultan relevantes para la conservación puesto que La Calera cuenta con dos áreas protegidas, la Reserva Natural Hidrica y Recreativa Bamba (que abarca unas 20 mil hectáreas ubicadas al Oeste de la ciudad de Córdoba, entre el embalse San Roque y el Este del Valle de Punilla) y la Reserva Natural de La Defensa La Calera que alberga parte del ecosistema del Espinal. En esta región se dan también importantes problemáticas socio-ambientales y territoriales devenidas de la minería, la expropiación de tierras para el desarrollo urbanístico e inmobiliario no planificado, contaminación hídrica, entre otras, lo que amenaza no sólo la diversidad biológica, sino también la transmisión cultural entre generaciones (Karlin et al., 2014; Martínez, 2015).

El presente trabajo focaliza principalmente el conocimiento y uso de recursos de un núcleo reducido de pobladores rurales que mantienen o han mantenido en el pasado reciente la práctica de cría y manejo ganadero, ya sea como pequeños productores o para uso doméstico. Esta selección obedece a que estos pobladores se aprovisionan y hacen un uso habitual de los recursos del bosque serrano, 
a la vez que experimentan de manera más ostensible el impacto de las transformaciones socio-ambientales locales que los pobladores neorrurales o urbanos. A pesar de ello, y a los fines de contar con un panorama más amplio de los saberes interculturales se trabajará también, aunque en contados casos, con saberes de otros pobladores rurales locales, tales como población nativa no campesina y neorrural.

El trabajo se planificó considerando el proceso de investigación y de obtención de datos etnobotánicos a campo (Albuquerque et al., 2010; Anderson et al., 2011).

Se trabajó combinando metodologías de las ciencias sociales y naturales, propias de los enfoques etnoecológicos, recurriendo a la complementariedad de los análisis cualitativos y cuantitativos (Green, 2001). Se aplicaron entrevistas abiertas y en profundidad, así como encuestas semiestructuradas a pobladores rurales. Se incluyeron registros etnográficos y datos de la observación participante (Guber, 2005), los que resultaron también de sustento para los análisis.

Se documentaron usos y aplicaciones locales de la vegetación con pobladores nativos y/o de muchos años de residencia en el lugar, con quienes se realizaron recorridas a campo y recolecciones referenciadas de las especies botánicas, especialmente aquellas que pudieran representar alguna ambigüedad en su identidad a partir de su nombre vulgar. Se procuró diversificar las entrevistas y recorridas a campo atendiendo al muestreo de diferentes unidades ambientales. Debido a lo escasamente representada que se halla la población rural, se realizó en un primer momento un abordaje en profundidad mediante entrevistas abiertas y extensas (Bernard, 2006) obteniendo información, listados y características, oportunidad de uso y otros aspectos de la flora alimenticia, en el marco de un estudio de etnobotánica general. La información de base permitió el diseño de encuestas semiestructuradas ad-hoc apropiadas para una valoración cuantitativa, las que consistieron en un enlistado o cheklist de 32 especies, conformada previamente a partir de las entrevistas abiertas. Se recurrió además a la técnica de recordatorio de uso, a los fines de indagar acerca del conocimiento y/o vigencia o no del uso de especies, procurando una mirada diacrónica de estas prácticas (Alexiades, 1996).

En relación con el muestreo se siguió un criterio no probabilístico, teniendo en cuenta las peculiaridades de un estudio social de tipo exploratorio. Asimismo se recurrió al muestreo por técnica de bola de nieve, y muestreo intencional de informantes calificados (Anderson et al., 2011). Se realizaron entrevistas en 30 unidades domésticas a informantes de entre 24 y 82 años de edad, un $53 \%$ de ellos del género masculino y un $47 \%$ femenino, en su mayoría pobladores nativos de La Calera (83\%), y un escaso porcentaje de población neorrural (17\%).

En lo concerniente a la identidad de los especímenes botánicos se partió de una colección de referencia del equipo de trabajo para la región, la que se amplió con otros nuevos no colectados, los que se preservaron y se determinaron mediante literatura especializada (Flora Vascular del Cono Sur, Flora Vascular de la República Argentina), consulta de botánicos especialistas, y/o corroboración de identidades en herbarios oficiales. Posteriormente las nuevas colectas fueron acondicionadas para depositarlas en el Herbario del Museo Botánico de Córdoba (CORD/IMBIV), siguiendo la nomenclatura propuesta en la Flora del Cono Sur según la base de datos disponible en línea por el Instituto de Botánica Darwinion.

Los datos acerca del conocimiento y uso de las especies se analizaron mediante estadística descriptiva y multivariada, considerando el conocimiento y el recordatorio de uso de cada especie y variables de análisis (edad, género, origen del poblador). Para la variable edad se consideraron tres categorías de análisis (20-45, 46-65 y 65-100 años), dos para categoría género (F y M) y dos para categoría origen del poblador (Nativos y Neorrurales). El tratamiento se realizó de manera individual para cada una de las variables (mediante un test de Chi Cuadrado) y de manera conjunta para las tres variables cruzando información con las especies y usos alimenticios mencionados (mediante un Análisis de Correspondencia Múltiple).

Para identificar factores que influencian la provisión y aprovechamiento de los recursos comestibles del bosque serrano en los ámbitos y población de estudio, se realizaron 
interpretaciones mediante un abordaje con métodos cualitativos. Para ello, previa transcripción de los registros de audio, se tomaron fragmentos de discurso, narrativas, expresiones de las entrevistas abiertas y en profundidad, y registros de diarios de campo, los que fueron luego codificados de acuerdo con categorías temáticas emergentes (Strauss \& Corbin, 1998), que dieron cuenta de los tópicos recurrentes y el consenso o pluralidad de visiones en particular a lo concerniente a: indicadores de cambio cultural, de impacto de los cambios socio-ambientales, causas de creciente desuso de los recursos etnobotánicos, entre otros.

\section{Resultados}

Recursos vegetales comestibles y alimentación

A lo largo de las entrevistas, se documentaron un total de 36 especies alimenticias (44\% de nativas y $56 \%$ de introducidas) y 42 aplicaciones comestibles. El listado detallado de especies y usos alimenticios puede consultarse en la Tabla 1.

Entre las aplicaciones y las especies conocidas por todos los entrevistados (Fig. 1) encontramos los frutos de Prosopis alba (algarrobo), Geoffroea decorticans (chañar), Morus alba (mora), Ficus carica (higuera), Opuntia ficus-indica (tuna), Salpichroa origanifolia (uvita del campo), Nasturtium officinale (berro) y los arropes de Opuntia ficusindica (tuna) (100\%); resultan también muy conocidos por más del $90 \%$ de entrevistados los frutos de Juglans regia (nogal), Celtis ehrenbergiana (tala), Sarcomphalus mistol (mistol) y Condalia spp. (piquillín). Entre las que menos se conocen, se encuentran la aloja de Condalia spp. (piquillín), aloja de Lithraea molleoides (molle), Amaranthus hybridus (ataco), Carduus sp. (cardo) y Bidens pilosa (amor seco), todos ellos con valores superiores al $80 \%$ de desconocimiento.

$\mathrm{Si}$ atendemos a las frecuencias relativas acerca de los recordatorios de usos (Fig. 2) se observa que, entre las especies más recientemente utilizadas encontramos Nasturtium officinale (berro), el fruto de Morus alba (mora) y Salpichroa origanifolia (uvita del campo) todas ellas consumidas en el último mes de la entrevista en más del 10\% de los casos; le siguen otras especies bastante consumidas en el transcurso del último año, entre ellas frutos de: Ficus carica (higuera), Lithraea molleoides (molle), Prosopis alba (algarrobo), Opuntia ficus-indica (tuna) (junto al arrope), Juglans regia (nogal), Geoffroea decorticans (chañar), Condalia spp. (piquillín) y Prunus persica (durazno silvestre).

Entre las especies menos consumidas, hace más de diez años o que nunca se consumieron se encuentran Robinia pseudoacacia (acacia blanca), Bidens pilosa (amor seco), Carduus sp. (cardo), Amaranthus hybridus (ataco), la aloja de Lithraea molleoides (molle) y de Prosopis alba (algarrobo), Broussonetia papyrifera (higuerilla), Rumex crispus (lengua de vaca), el látex de Ficus carica (higuera) ${ }^{4}$, la aloja de Condalia spp. (piquillín), Portulaca oleracea (verdolaga), Celtis ehrenbergiana (tala) y Araujia brachystephana (tasi).

En la Fig. 3 vemos como resultan de mayor peso las gráficas relacionadas con la pérdida del uso o disminución de la vigencia (5-10 años, $>10$ años o nunca) respecto de las de uso más reciente ( $<1$ mes $<1$ año, 1-5 años). Esto estaría indicando una tendencia a la erosión cultural en términos de uso de estas plantas.

Relevancia e importancia cultural de las especies Diferencias en el conocimiento y uso de plantas alimenticias de acuerdo a la edad, género y origen de los entrevistados

Los resultados indican diferencias en el conocimiento entre los entrevistados de acuerdo a las tres categorías de edades predefinidas, considerando la totalidad de las plantas y usos alimenticios. Se observan diferencias en las frecuencias de citas de plantas comparando la frecuencia total de citas entre los grupos etarios $\left(\chi^{2}=7,74 ; p=0,0208\right)$. Asimismo se observan diferencias en la proporción de citas de especies entre mujeres y hombres $\left(\chi^{2}=\right.$ $5,47 ; p=0,0193)$. Finalmente, al comparar el conocimiento entre informantes nativos y neorrurales, la frecuencia total de citas no resultó significativamente diferente en los grupos de informantes $\left(\chi^{2}=1,89 ; p=0,169\right)$.

\footnotetext{
${ }^{4}$ Se emplea para cuajar la leche y fabricar quesos.
} 
Tabla 1. Especies vegetales comestibles.

Table 1. Edible plant species.

\begin{tabular}{|c|c|c|c|}
\hline Nombre vulgar & Especie y familia & Usos & Observaciones \\
\hline Acacia blanca & $\begin{array}{l}\text { Robinia pseudoacacia L. } \\
\text { (Fabaceae) }\end{array}$ & $\begin{array}{l}\text { Consumo directo de la flor, } \\
\text { torrejas, picada, cruda y frita. } \\
\text { Licor }\end{array}$ & Adventicia \\
\hline $\begin{array}{l}\text { Achicoria del } \\
\text { campo }\end{array}$ & $\begin{array}{l}\text { Cichorium intybus L. } \\
\text { (Asteraceae) }\end{array}$ & Ensalada, torreja, tortilla & Adventicia \\
\hline Aguaribay & $\begin{array}{l}\text { Schinus areira L. } \\
\text { (Anacardiaceae) }\end{array}$ & Pimienta, elaboración de té & Nativa \\
\hline Albarillo o pata & $\begin{array}{l}\text { Ximenia americana L. var. } \\
\text { americana (Olacaceae) }\end{array}$ & $\begin{array}{l}\text { Se lo consume en forma } \\
\text { directa o se lo prepara como } \\
\text { un durazno en compota, } \\
\text { hervido con azúcar }\end{array}$ & $\begin{array}{l}\text { Nativa. Es de difícil } \\
\text { hallazgo, escaso, } \\
\text { sin embargo, un } \\
\text { entrevistado señala } \\
\text { haber recogido en la } \\
\text { zona cerca de } 5 \mathrm{~kg} \\
\text { durante el } 2015\end{array}$ \\
\hline Algarrobo blanco & $\begin{array}{l}\text { Prosopis alba Griseb. var. } \\
\text { alba (Fabaceae) }\end{array}$ & $\begin{array}{l}\text { Aloja, patay, arrope y } \\
\text { consumo directo. Alfajores, } \\
\text { panes. Forraje. Helado. }\end{array}$ & $\begin{array}{l}\text { Nativa. Se le tiene } \\
\text { mucha estima y se lo } \\
\text { proteje }\end{array}$ \\
\hline Amor seco & $\begin{array}{l}\text { Bidens pilosa } \mathrm{L} . \\
\text { (Asteraceae) }\end{array}$ & $\begin{array}{l}\text { Frito, acompañando bife a } \\
\text { la criolla. Consumo de la flor } \\
\text { (polen) como azafrán }\end{array}$ & Nativa \\
\hline Ataco o bledo & $\begin{array}{l}\text { Amaranthus hybridus } \\
\text { L. subsp. hybridus } \\
\text { (Amaranthaceae) }\end{array}$ & $\begin{array}{l}\text { Con guayacán y quiebra- } \\
\text { arado para el empacho. En } \\
\text { ensalada }\end{array}$ & $\begin{array}{l}\text { Adventicia. Es más } \\
\text { conocido como } \\
\text { alimento para } \\
\text { animales (cerdo) }\end{array}$ \\
\hline Berro & $\begin{array}{l}\text { Nasturtium officinale W. T. } \\
\text { Aiton (Brassicaceae) }\end{array}$ & $\begin{array}{l}\text { Torrejas, ensaladas, sopa, } \\
\text { acompañando fideos }\end{array}$ & $\begin{array}{l}\text { Adventicia. Muy } \\
\text { estimada. Cuando da } \\
\text { flor es fuerte y duro }\end{array}$ \\
\hline Cardo & Carduus sp. (Asteraceae) & $\begin{array}{l}\text { Acompañando guisos o bife } \\
\text { a la criolla (hoja cocida sabe } \\
\text { amarguita y saladita), torreja }\end{array}$ & $\begin{array}{l}\text { Naturalizada. } \\
\text { Considerada plaga }\end{array}$ \\
\hline Chañar & $\begin{array}{l}\text { Geoffroea decorticans } \\
\text { (Gillies ex Hook. \& Arn.) } \\
\text { Burkart (Fabaceae) }\end{array}$ & $\begin{array}{l}\text { Consumo directo, arrope, } \\
\text { jalea, té, jarabe, licor, helado }\end{array}$ & Nativa \\
\hline Diente de león & $\begin{array}{l}\text { Taraxacum officinale G. } \\
\text { Weber ex F. H. Wigg. } \\
\text { (Asteraceae) }\end{array}$ & Ensalada, torreja & $\begin{array}{l}\text { Adventicia. También } \\
\text { es conocido como } \\
\text { achicoria silvestre. } \\
\text { "Es un yuyo" }\end{array}$ \\
\hline Durazno silvestre & $\begin{array}{l}\text { Prunus persica (L.) } \\
\text { Batsch (Rosaceae) }\end{array}$ & $\begin{array}{l}\text { Consumo directo, dulces, } \\
\text { compotas y pelones. Vinagre } \\
\text { con la cáscara. Licuado }\end{array}$ & $\begin{array}{l}\text { Adventicia. Se } \\
\text { asilvestró en algunas } \\
\text { quebradas a las que } \\
\text { la gente concurre } \\
\text { para su recolección }\end{array}$ \\
\hline Frutilla silvestre & $\begin{array}{l}\text { Duchesnea indica } \\
\text { (Andrews) Focke } \\
\text { (Rosaceae) }\end{array}$ & $\begin{array}{l}\text { Consumo directo y con } \\
\text { azúcar como postre }\end{array}$ & $\begin{array}{l}\text { Adventicia. Se le } \\
\text { tiene desconfianza } \\
\text { porque se teme sea } \\
\text { venenosa }\end{array}$ \\
\hline Higuera & $\begin{array}{l}\text { Ficus carica L. } \\
\text { (Moraceae) }\end{array}$ & $\begin{array}{l}\text { Consumo directo, pasas, } \\
\text { dulce, en almíbar. Látex para } \\
\text { cuajar la leche, ricota }\end{array}$ & Adventicia \\
\hline
\end{tabular}




\begin{tabular}{|c|c|c|c|}
\hline Nombre vulgar & Especie y familia & Usos & Observaciones \\
\hline Higuerilla & $\begin{array}{l}\text { Broussonetia papyrifera } \\
\text { (L.) Vent. (Moraceae) }\end{array}$ & $\begin{array}{l}\text { Consumo directo (pelos } \\
\text { jugosos y dulces del fruto) }\end{array}$ & Adventicia \\
\hline Hinojo & $\begin{array}{l}\text { Foeniculum vulgare Mill. } \\
\text { (Apiaceae) }\end{array}$ & $\begin{array}{l}\text { Consumo directo, agregado al } \\
\text { mate, tallos como escalope, } \\
\text { ensalada, torreja. Fumado } \\
\text { cuando seco. Semillas en el } \\
\text { pan }\end{array}$ & $\begin{array}{l}\text { Adventicia. Antes era } \\
\text { abundante, "se está } \\
\text { perdiendo". Comida } \\
\text { para los conejos. En } \\
\text { orillas de acequias } \\
\text { y ríos }\end{array}$ \\
\hline $\begin{array}{l}\text { Hongos de coco y } \\
\text { molle }\end{array}$ & $\begin{array}{l}\text { Phlebopus bruchii (Speg.) } \\
\text { Heinem. \& Rammeloo } \\
\text { (Boletinellaceae) }\end{array}$ & $\begin{array}{l}\text { Consumido fresco y seco, } \\
\text { en escabeches y en vinagre, } \\
\text { salsas, guisos, milanesa }\end{array}$ & $\begin{array}{l}\text { Dificultad para } \\
\text { recolectar debido a } \\
\text { su escasez, producto } \\
\text { de incendios y } \\
\text { reducción del bosque } \\
\text { nativo. "Antes volvían } \\
\text { con canastos llenos". } \\
\text { Muy apreciado }\end{array}$ \\
\hline Hongos de pino & $\begin{array}{l}\text { Suillus granulatus (L.) } \\
\text { Roussel (Suillaceae) }\end{array}$ & $\begin{array}{l}\text { Consumo fresco o seco, } \\
\text { guisos }\end{array}$ & Exótico \\
\hline Lengua de vaca & $\begin{array}{l}\text { Rumex crispus L. } \\
\text { (Polygonaceae) }\end{array}$ & $\begin{array}{l}\text { Ensalada, torreja, tortilla. } \\
\text { En el mate "bueno para el } \\
\text { estómago" }\end{array}$ & $\begin{array}{l}\text { Adventicia. Simil } \\
\text { acelga }\end{array}$ \\
\hline Mistol & $\begin{array}{l}\text { Sarcomphalus mistol } \\
\text { (Griseb.) Hauenschild } \\
\text { (Rhamnaceae) }\end{array}$ & $\begin{array}{l}\text { Consumo directo, arrope, } \\
\text { café }\end{array}$ & $\begin{array}{l}\text { Nativa. Muy escaso } \\
\text { en la zona, y se } \\
\text { comenta que no dan } \\
\text { frutos }\end{array}$ \\
\hline Molle & $\begin{array}{l}\text { Lithraea molleoides (Vell.) } \\
\text { Engl. (Anacardiaceae) }\end{array}$ & $\begin{array}{l}\text { Principalmente como aditivo } \\
\text { del mate, consumo directo. } \\
\text { Aloja y licor del fruto }\end{array}$ & $\begin{array}{l}\text { Nativa. Muy } \\
\text { apreciado. } \\
\text { Disminución de la } \\
\text { fructificación }\end{array}$ \\
\hline Mora & Morus alba L. (Moraceae) & $\begin{array}{l}\text { Consumo directo y dulces. } \\
\text { Tartas, repostería }\end{array}$ & Adventicia \\
\hline Nogal & $\begin{array}{l}\text { Juglans regia L. } \\
\text { (Juglandaceae) }\end{array}$ & $\begin{array}{l}\text { Consumo directo, nueces } \\
\text { confitadas, elaboración de } \\
\text { leche, acompañando diversas } \\
\text { recetas }\end{array}$ & Adventicia \\
\hline Pasionaria & $\begin{array}{l}\text { Passiflora mooreana } \\
\text { Hook. f., } \\
\text { Passiflora caerulea L. } \\
\text { (Passifloraceae) }\end{array}$ & $\begin{array}{l}\text { Consumo directo del fruto, } \\
\text { té de hojas, flor en ensalada } \\
\text { (cfr.) }\end{array}$ & Nativas \\
\hline Piquillín & $\begin{array}{l}\text { Condalia microphylla Cav. } \\
\text { (Rhamnaceae) }\end{array}$ & Consumo directo, arrope & $\begin{array}{l}\text { Endémica. Se } \\
\text { está perdiendo, se } \\
\text { queman y secan. } \\
\text { "Empieza a cantar la } \\
\text { chicharra, madura el } \\
\text { piquillín en enero" }\end{array}$ \\
\hline Quiscaludo o tunilla & $\begin{array}{l}\text { Opuntia sulphurea } \\
\text { Gillies ex Salm-Dyck var. } \\
\text { sulphurea (Cactaceae) }\end{array}$ & Consumo directo, arrope & Nativa \\
\hline Tala & $\begin{array}{l}\text { Celtis ehrenbergiana } \\
\text { (Klotzsch) Liebm. } \\
\text { var. ehrenbergiana } \\
\text { (Celtidaceae) }\end{array}$ & $\begin{array}{l}\text { Consumo directo, o una } \\
\text { ramita en leche para el } \\
\text { empacho }\end{array}$ & Nativa \\
\hline
\end{tabular}




\begin{tabular}{|c|c|c|c|}
\hline Nombre vulgar & Especie y familia & Usos & Observaciones \\
\hline Tasi o doca & $\begin{array}{l}\text { Araujia brachystephana } \\
\text { (Griseb.) Fontella \& } \\
\text { Goyder (Apocynaceae) }\end{array}$ & $\begin{array}{l}\text { Consumo directo, para cortar } \\
\text { la leche }\end{array}$ & $\begin{array}{l}\text { Nativa. "Hay que } \\
\text { consumirlo cuando } \\
\text { es chiquito". "Para las } \\
\text { mujeres" }\end{array}$ \\
\hline Tuna & $\begin{array}{l}\text { Opuntia ficus-indica } \\
\text { (L.) Mill. f. ficus-indica } \\
\text { (Cactaceae) }\end{array}$ & $\begin{array}{l}\text { Consumo directo, arrope, } \\
\text { arrope con quesillos }\end{array}$ & Adventicia \\
\hline Uvita del campo & $\begin{array}{l}\text { Salpichroa origanifolia } \\
\text { (Lam.) Baill. (Solanaceae) }\end{array}$ & Consumo directo & $\begin{array}{l}\text { Nativa. Muy } \\
\text { apreciada. "Hay poco } \\
\text { ya no está como } \\
\text { antes" }\end{array}$ \\
\hline Verdolaga & $\begin{array}{l}\text { Portulaca oleracea L. } \\
\text { (Portulacaceae) }\end{array}$ & Torrejas, ensalada & Adventicia \\
\hline Zarzamora & $\begin{array}{l}\text { Rubus ulmifolius Schott } \\
\text { (Rosaceae) }\end{array}$ & $\begin{array}{l}\text { Consumo directo, dulce, en } \\
\text { almíbar, chutney }\end{array}$ & $\begin{array}{l}\text { Adventicia. } \\
\text { Denominada plaga } \\
\text { o invasora. Algunos } \\
\text { tienen desconfianza y } \\
\text { la creen venenosa }\end{array}$ \\
\hline $\begin{array}{l}\text { *Jínjoli, manzanita } \\
\text { (azufaifo) }\end{array}$ & $\begin{array}{l}\text { Ziziphus jujuba Mill. } \\
\text { (Rhamnaceae) }\end{array}$ & Consumo directo & $\begin{array}{l}\text { Exótica. Hallazgo } \\
\text { en la zona, muy } \\
\text { preciada en su } \\
\text { distribución original } \\
\text { por sus propiedades } \\
\text { nutricionales y } \\
\text { medicinales }\end{array}$ \\
\hline${ }^{*}$ Verdolaga & $\begin{array}{l}\text { Talinum paniculatum } \\
\text { (Jacq.) Gaertn } \\
\text { (Portulacaceae) }\end{array}$ & Idem Portulaca oleracea & $\begin{array}{l}\text { Adventicia. Se } \\
\text { consume en torrejas, } \\
\text { similar a Portulaca } \\
\text { oleracea }\end{array}$ \\
\hline *Ají puta-pario & $\begin{array}{l}\text { Capsicum chacoense } \\
\text { Hunz. (Solanaceae) }\end{array}$ & Condimento & $\begin{array}{l}\text { Nativa. Se perdió } \\
\text { mucho, casi no se } \\
\text { encuentra }\end{array}$ \\
\hline $\begin{array}{l}{ }^{*} \text { Menta, yerba } \\
\text { buena }\end{array}$ & $\begin{array}{l}\text { Mentha spp. } \\
\text { (Lamiaceae) }\end{array}$ & $\begin{array}{l}\text { Condimento, té, con leche, en } \\
\text { mate, licor de menta }\end{array}$ & Adventicia \\
\hline
\end{tabular}

* Otras especies mencionadas en el transcurso del trabajo o surgidas de la observación de huertos y espacios peridomésticos, que no fueron incluidas en entrevistas semiestructuradas

En la Fig. 4 se observa un Análisis de Correspondencia Múltiple en el que se visualizan las dos dimensiones de la tabla de contingencia que pertenece al cruce de las variables "recordatorio de uso", "género", "origen del entrevistado" y "especies y usos alimenticios". Se puede observar en el primer eje (con una inercia del $43 \%$ ) que se oponen claramente el perfil de especies y usos que desconocen como alimentos, con respecto a aquellos con algún tipo de mención de uso; asimismo se observa oposición entre los géneros y el origen de los entrevistados. Se ponen de relevancia en el extremo derecho del eje 1 horizontal del gráfico, especies y usos que muchos de los informantes refirieron no conocer ni usar, como las alojas de Condalia spp. (piquillín), de Lithraea molleoides (molle) y de Prosopis alba (algarrobo), Ximenia americana (albarillo), Amaranthus hybridus (ataco), Carduus sp. (cardo), Bidens pilosa (amor seco), Portulaca oleracea (verdolaga), Rumex crispus (lengua de vaca), látex de Ficus carica (higuera), arrope de Condalia spp. (piquillín), Schinus areira (aguaribay), Opuntia sulphurea (quiscaludo) y Araujia 


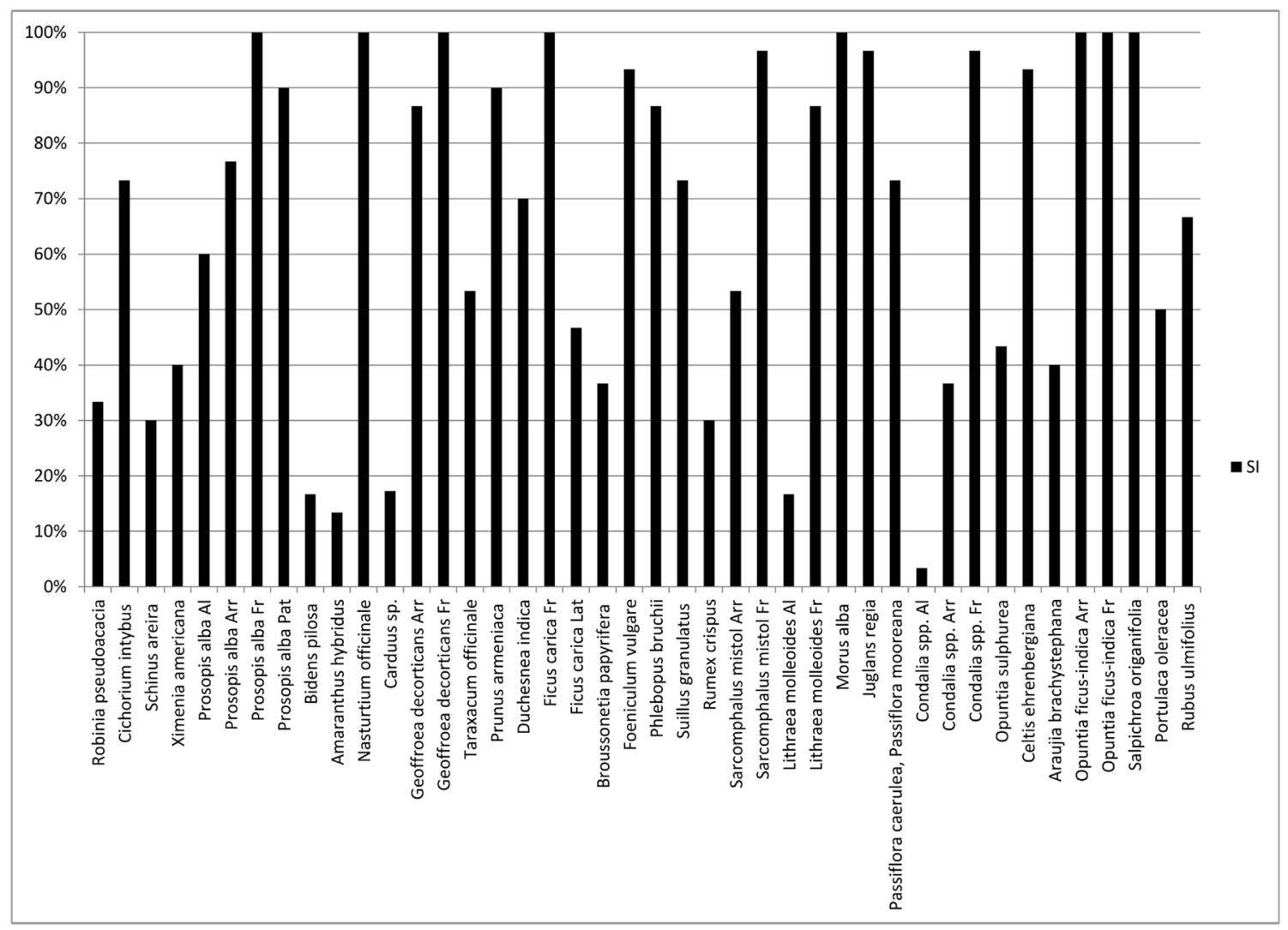

Fig. 1. Frecuencias relativas acerca del conocimiento de las especies y usos alimenticios en pobladores rurales de La Calera ( $n=30$ unidades domésticas).

Fig. 1. Relative frequencies about the knowledge of the species and food uses in rural inhabitants of La Calera ( $\mathrm{n}=30$ domestic units).

brachystephana (tasi). En el centro de las coordenadas se encuentran aquellas especies y usos cuyos consumos fueron referidos con frecuencias de consumo mayores a los diez años, por lo que su uso se encuentra decreciendo o con riesgo de extinción de la experiencia en el lugar, es el caso de arropes de Prosopis alba (algarrobo), Foeniculum vulgare (hinojo), fruto de Sarcomphalus mistol (mistol), Phlebopus bruchii (hongos de coco y molle), Passiflora mooreana y P. caerulea (pasionaria), fruto de Geoffroea decorticans (chañar), Duchesnea indica (frutillita del campo), Celtis ehrenbergiana (tala), arrope de Sarcomphalus mistol (mistol) y otros. Finalmente en el extremo izquierdo del eje 1 se encuentran especies de uso más reciente como Salpichroa origanifolia (uvita del campo), Juglans regia (nogal), fruto de Ficus carica (higo), de Morus alba (mora), arrope y fruto de Opuntia ficus-indica (tuna) y Nasturtium officinale (berro).

Aspectos culturales de la alimentación en población rural de La Calera

A lo largo del trabajo se documentó un total de 121 preparados alimenticios, en algunos casos con sus respectivas recetas, los que se encuentran listados en el Anexo 1. El análisis de las narrativas permitió identificar información que fue nucleada en torno a los siguientes tópicos:

a) Categorías locales de clasificación

A lo largo del proceso de investigación emergieron diferentes categorías nativas locales, para dar cuenta y distinguir el empleo de productos alimenticios de la flora nativa, denominados 


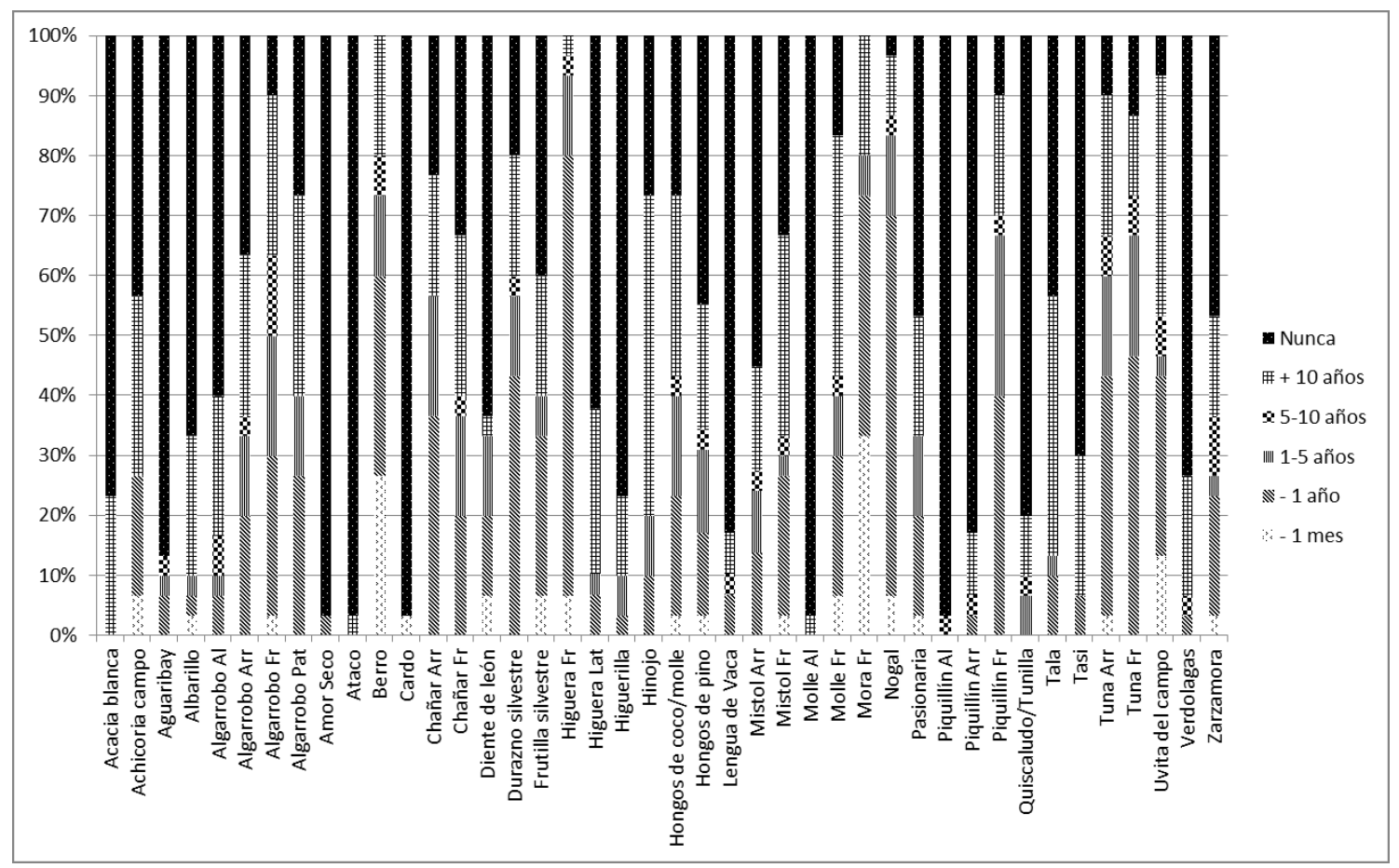

Fig. 2. Frecuencias relativas acerca de los recordatorios de usos de las especies y aplicaciones alimenticias en pobladores rurales de La Calera ( $\mathrm{n}=30$ unidades domésticas).

Fig. 2. Relative frequencies about recall of uses of species and food applications in rural inhabitants of La Calera ( $\mathrm{n}=$ 30 domestic units).

"fruta/o" (ej. frutos de tala, mistol, algarroba, piquillín), respecto de las "comida" o "comidacomida" (ej. locro u otros productos elaborados con maíz, trigo, sus harinas y/o carne). Por otra parte, en el caso de las "verduras de hoja" (ej. diente de león, lengua de vaca, tallos de hinojo y cardo) se remite siempre a su semejanza con la "acelga", al referir su parecido en cuando a morfología, textura y a que suelen prepararse en forma de torrejas. La acelga en este caso se utiliza como una especie de valor prototípico ${ }^{5}$ en términos cognitivos, en tanto es la que mejor explica al grupo de las "verduras de hoja". Fuera de estas categorías no se encontraron otras de

${ }^{5}$ De acuerdo a Rosch et al. (1976) las categorizaciones en base al uso de prototipos, como en este caso, es una forma de identificar las propiedades que son predecibles para agrupar y al mismo tiempo permiten discriminar elementos semejantes (como el nombre incluso) y como una forma de economía cognitiva en tanto permite reducir las infinitas diferencias entre estímulos a formas comportamentales y congnitivamente posibles de manejar por la mente humana. ninguna índole clasificatoria, así como tampoco la existencia de clases sin etiquetas o categorías encubiertas, dando cuenta de la vigencia de una etnotaxonomía muy simple.

"sacábamos un racimo de flores y nos morfábamos las flores, bueno y eso con eso mi vieja nos sabia llevar, nosotros lo juntábamos eso y mi vieja lo picaba no sé cómo no me acuerdo si lo hervía o no pero sé que lo picaba y hacia un menjunje ahi, como digamos más o menos seria como ahora se hace la acelga... yo no sé si lo hervía o no, pero yo sé que lo metía... No lo fritaba como una torreja, bueno pero yo no sé como ser la acelga si se la cocina antes y después se la hace... no y si las madres usaban todo porque no querían tirar nada" (Lalo P., Paraje Boca Dos, XI-2016)

“-Lengua de vaca-Si como ensalada también se puede hacer torreja se usa más o menos como la acelga después de hervir haces torreja y el berro también sirve para sopa esas hojas duras tronco duro se las echa como la acelga al puchero 


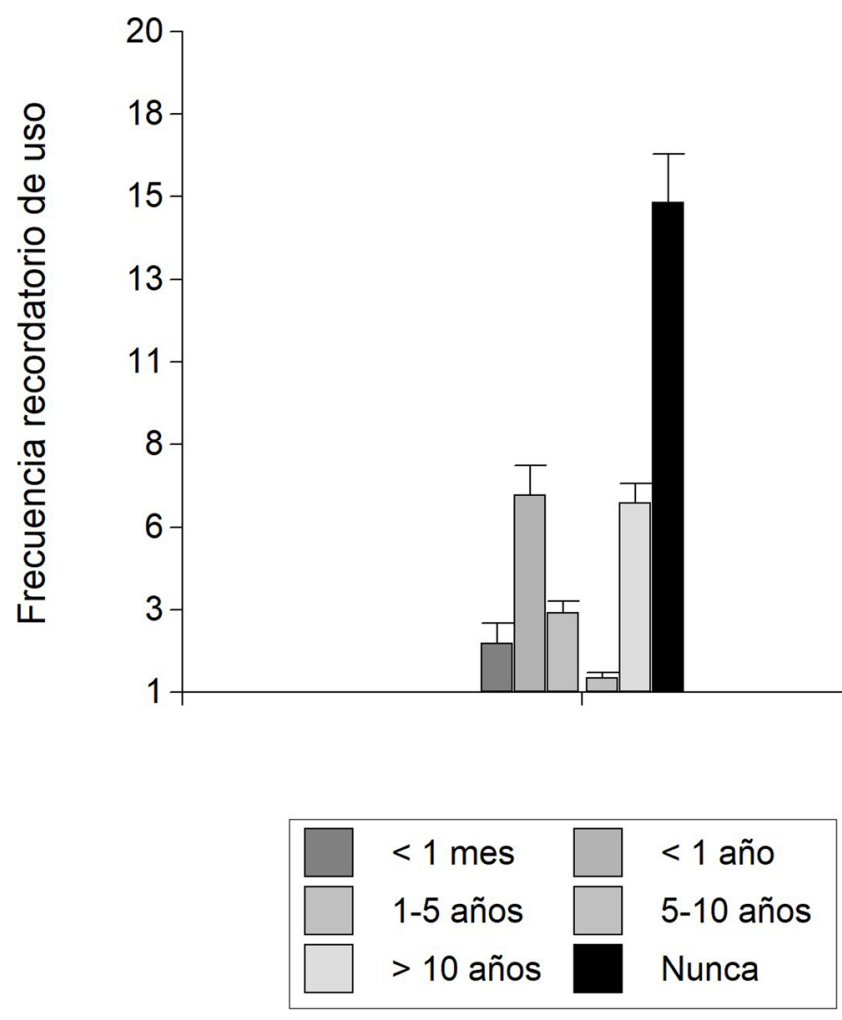

Fig. 3. Frecuencia relativa de los recordatorios de usos de todas las especies.

Fig. 3. Relative frequency of use reminders for all species.

y sale el gusto todo como el caldo con el gusto a berro, si buenaso es" (Lalo P. Paraje Boca Dos, $X I-2016)$

"El tallo (del hinojo) hecho escalopin, escalope, claro se corta la hoja y se fríe el tallo ancho, como el tallo de la acelga usted corta la hoja de la acelga la cocina la hace torreja lo que usted quiera cierto y el tallo, la parte ancha del tallo de la acelga usted lo sancocha y prepárelo con huevo y harina y prepárelo y después dígame sino es un pescado" (Carlos F., Villa El Diquecito, XI-2016)

Otro aspecto prototípico de los alimentos que se consideraban indispensables para la mesa cotidiana, es el caso de la sopa, la que incluye en su composición algunos vegetales:

"La sopa no faltaba era importante la sopa... yo uso si, yo siempre la hago, la sopa en principal sí la uso mucho a la sopa" (Catalina C., Villa El Diquecito, XII-2016)
"La sopa en mi casa era sagrada, mami hacía porque papi le gustaba todo los días tomar la sopa" (Mirta C., La Mesada, XII-2016)

b) La trayectoria de los alimentos

Diversos informantes recuerdan y aún hoy es práctica frecuente proveerse de alimentos desde el Noroeste de Córdoba (Villa de Soto, Deán Funes, Cruz del Eje) y de otras provincias del Norte o Noroeste del país (La Rioja, Tucumán, Catamarca, Santiago del Estero, Salta y Jujuy). Entre los productos mencionados se encuentran el patay de algarrobo y el arrope de tuna cuando viajan a la procesión de San Roque en Villa de Soto; el maní y el mistol en fruto y arropes. Estos espacios constituyen verdaderos circuitos que enriquecen y contribuyen a sostener el aprovechamiento y uso de los productos del monte.

“- ¿Y el patay lo ha preparado alguna vuelta? 


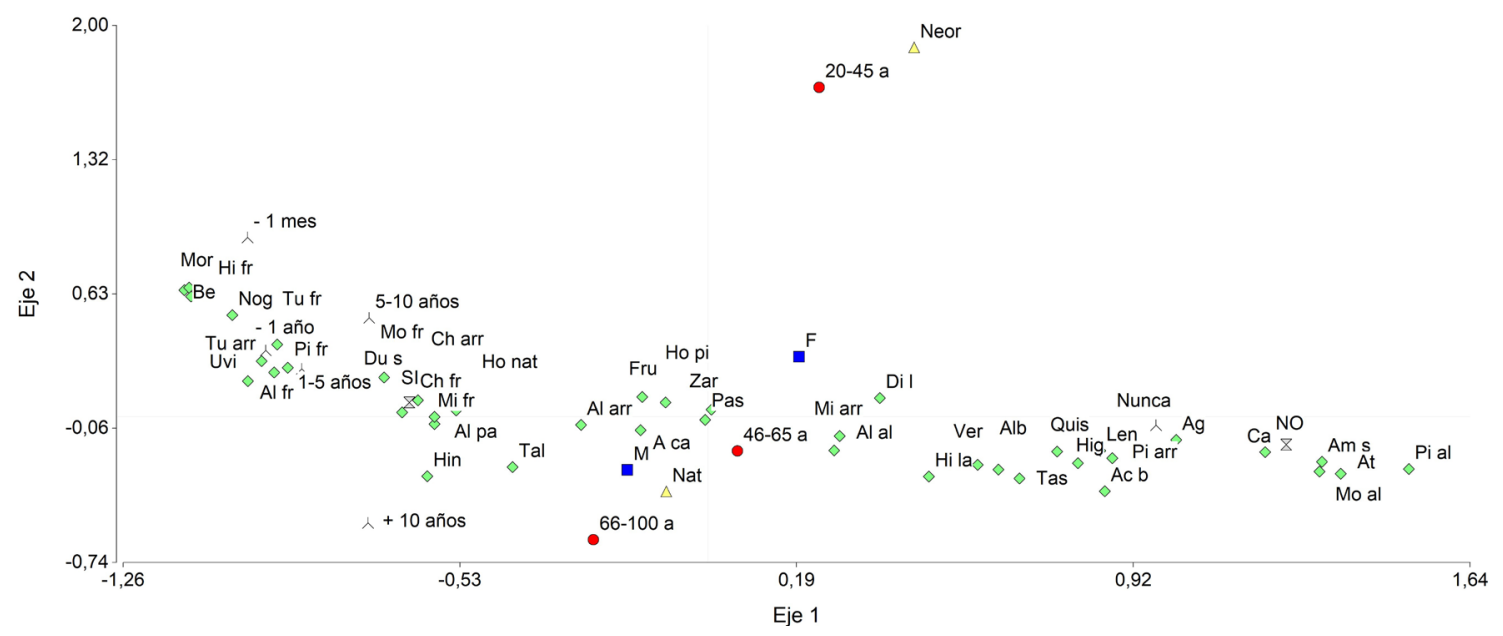

Fig. 4. Biplot correspondiente al Análisis de Correspondencia Múltiple para las variables "Género", "Recordatorio de Uso", "Origen de los entrevistados" y "Especies y usos alimenticios". (Inercia o valor Chi cuadrado dividido por gran total de la tabla de contingencia 43\%) Acacia blanca, Ac b; Achicoria campo, A ca; Aguaribay, Ag; Albarillo, Alb; Algarrobo Fruta, Al fr; Algarrobo Aloja, Al al; Algarrobo Patay, Al pa; Algarrobo Arrope, Al arr; Amor Seco, Am s; Ataco, At; Berro, Be; Cardo, Ca; Chañar Fruto, Ch fr; Chañar Arrope, Ch arr; Diente de león, Di 1; Durazno silvestre, Du s; Frutilla silvestre, Fru; Higuera Lat, Hi la; Higuera Fruta, Hi fr; Higuerilla, Hig; Hinojo, Hin; Hongos de coco/ molle, Ho nat; Hongos de pino, Ho pi; Lengua de Vaca, Len; Mistol Fruto, Mi fr; Mistol Arr, Mi arr; Molle Fruto, Mo fr; Molle Aloja, Mo al; Mora, Mor; Nogal, Nog; Pasionaria, Pas; Piquillín Fruto, Pi fr; Piquillín Arrope, Pi arr; Piquillín Aloja, Pi al; Quiscaludo/Tunilla, Quis; Tala, Tal; Tasi, Tas; Tuna Fruto, Tu fr; Tuna Arrope, Tu arr; Uvita del campo, Uvi; Verdolagas, Ver; Zarzamora, Zar.

Fig. 4. Bi Plot corresponding to the Multiple Correspondence Analysis for the variables "Gender", "Recall of Use", "Origin of the interviewees" and "Species and food uses". (Inertia or Chi-square value divided by grand total of the contingency table 43\%)

-No, mi mujer hacía en Tucumán porque era tucumana ella lo hacia allá no acá no. - ¿Usted lo llegó a probar al patay? -Compraba un redondo así, en Calera sabia comprar y ahora ya no venden más. En Santiago se hacía mucho el patay y mi mujer lo sabía hacer cuando era chica en Tucumán en latitas de sardinas, dice que ahi hacía ella el patay" (Carlos K., Casa Bamba, XI-2016)

"- (arrope de chañar) hace tres meses me lo trajeron de Cruz del Eje, igual que los productos de algarroba" (Carlos F., Villa El Diquecito, XI-2016)

¿Y cuándo van, qué productos traen de La Rioja para comer? "...si ahí trajimos el arrope y miel, de tuna saben traer y después el otro, arrope de miel, de chañar... vino patero... si vos sabes que yo tenía mi suegro que a él le traían de la costa decía él, no sé dónde queda, en La Rioja porque antes lo hacian casero..." (Mirta C., La Mesada, XII-2016)

c) La valoración del consumo por su sabor $u$ otras características
Otros aspectos que se resaltan en los relatos y entrevistas, tanto de manera explícita como en su contenido paralingüístico, son los señalamientos, entonaciones o énfasis que aparecen en relación con el sabor de algunas especies comestibles. Son valorados y especialmente o enfáticamente señalados por su exquisitez o por ser ricos (ya sea por su sabor o textura) los "hongos de coco/ molle", la "uvita del campo", el "piquillín", el "albarillo" y la "algarroba". Así lo ponen de manifiesto algunos relatos como los que siguen:

"Al frutito (del albarillo) cuando sé ir en verano a buscar peperina así, pero es muy muy esporádico eso es casi como diríamos que no, pero sé que se come, alguna veces lo hemos comido, muy rico eh, cuando está maduro es ricaso" (Lalo P. Paraje Boca Dos, XI-2016)

"ehh es riquísima la uvita del campo" (Carlos F., Villa El Diquecito, XI-2016)

"Al diente de león como ensalada, como es amarguita a mí me gusta así amarguita..." "la 
lengua de vaca tiene un gustito saladito y es ricasa” (Lalo P., Paraje Boca Dos, XI-2016)

"Si el berro si, yo cuando me enteré que tenía hierro siempre buscaba la masa o algo que tenga hierro abajo pero no había nada... eso viene de conocimiento de antes que... calculo que se comía de que nadie sabía que era bueno por el hierro pero como es rico, medio picantito, bueno yo a ese si lo hago torreja con el berro crudo porque ahi le sale bien el sabor, vos lo picas chiquito y si es viejo el berro mejor, sacas el tronco duro lo picas bien chiquitito, haces el menjunje con harina, la cebolla bien chiquitita picada y pero salen espectacular las torrejas..." (Lalo P. Paraje Boca Dos, XI-2016)

"El molle es una cosa que yo no lo puedo ni pasar cerquita me flecha, me hace bosta, pero el molle para tomar mate para hacer jalea, jalea de molle, para tomar mate es la cosa más rica ... el molle échele 4 o 5 pepitas 6 pepitas esas en el mate, ijjoo papá!!...” (Carlos F., Villa El Diquecito, XI-2016)

“-ese (piquillín) lo juntábamos de la planta y lo comíamos -cuando está guardado queda muy rico,- lo poníamos en la heladera más rico se ponía jaja”. -¿No hacian arrope? "-no daban tiempo jaja -cuando buscaba para el arrope no había ya para el arrope; es que nosotros llevábamos para juntar piquillín y cuando llegaba a la casa llegaba casi vacio -si ese negro grandote es el más rico, bien dulce -es riquísimo, hay otro rojo también..." (Familia G.; Lorenzo, Norma y Elvira, Villa El Diquecito, XII-2016)

"Viste que es riquísimo el molle en el mate" (Elvira R., Villa El Diquecito, XII-2016)

\section{d) Comensalidad}

En la labor de campo pudimos identificar también algunos rasgos característicos del modo en que se comparten alimentos, asociados fundamentalmente a fechas típicas. Así, para las fechas patrias resulta casi obligado la elaboración y consumo de locro y empanadas o asado en diferentes modalidades (lechón, cabrito, vaca asada o con cuero, etc).

“y bueno puede ser si hay una reunión de 20, 30 personas hago locro empanadas eh este que es parecido al locro, buseca". -¿qué otras fechas son importantes para la comida? "-Para mí, todas las fechas son importantes, por ejemplo, yo allá en las Paredes hago el 25 de mayo o el 20 de junio o el 9 de julio yo hago locro ahi y después para $1^{\circ}$ de año siempre nos juntamos ahi todos eh yo hago asado, empanadas dulces y saladas, igual que usted consigue un zapallo bueno, bueno, lindo lo parte a la mitad y le saca todo el semillaje y lo pone al rescoldo" (Carlos F., Villa El Diquecito, XI-2016)

"yo soy criollo, yo hago de todo, siempre hago locro, con maiz, con trigo, poroto, arveja partida y después ya sabe la carne de chancho las patitas de chancho cuerito de chancho eh zapallo criollo, no calabacín eso queda dulce...pero son vagos (te lo digo francamente) uh vos sabes que tengo ganas de comer una mazamorra, le digo yo pero por mi hecha ahh que rico, yo hago todo esta vez yo les invito a todos, les voy a hacer una mazamorra, le hice una mazamorra y allá les lleve... yo hago todo siempre los 20 de junio, los 9 de julio o el 25 de mayo yo hago comidas típicas" (Carlos F., Villa El Diquecito, XI-2016)

Las pautas de reciprocidad o exigencias retributivas no podían faltar en la dinámica de los vínculos familiares y de vecindad, así lo expresan los siguientes relatos:

"Uhhh, licores hacia de menta, de peperina, de mandarina, se me perdian ah ajaja, si el de menta lo regalaba... a uno en donde trabajaba... me lo perdian, me lo robaban..." (Carlos K., Casa Bamba, XI-2016)

¿Hace mucho que no hace (jalea de molle)? “-No, no, no hago... yo puedo hacer todo eso porque yo tengo habilidad tengo todo eso, pero no, no lo quiero hacer porque ya vienen, yo preparo ya me ven que estoy y olfatean y ya uhh que estás haciendo un poquito de esto y no ya ni lo pruebo yo..." (Carlos F., Villa El Diquecito, XI-2016)

Factores que influencian la provisión y aprovechamiento de los recursos comestibles del bosque serrano en los ámbitos y población de estudio

A continuación presentamos un análisis de fragmentos de discurso, narrativas, expresiones codificados de acuerdo con categorías emergentes, es decir por núcleos temáticos que permitían su agrupamiento o categorización. Los mismos dieron cuenta de los tópicos recurrentes y el consenso o pluralidad de visiones 


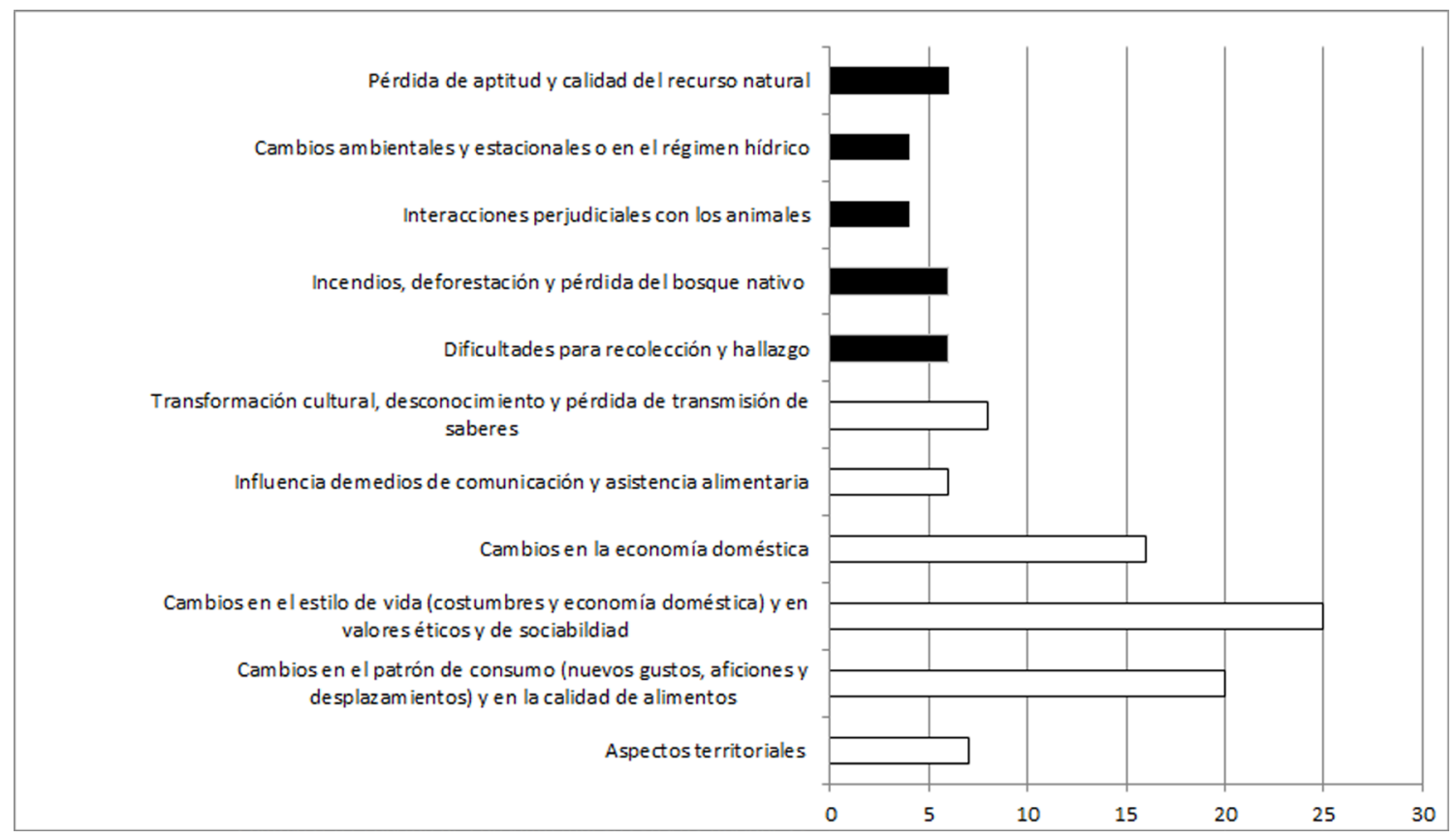

Fig. 5. Frecuencia de menciones en relatos y narrativas de las razones socioculturales (blancas) y ambientales (negras) vinculadas a las transformaciones en la alimentación.

Fig. 5. Frequency of mentions in stories and narratives of social (white) and environmental (black) reasons linked to changes in feeding.

en torno a dos grandes temas: las razones socioculturales y las ambientales vinculadas a estas transformaciones en la alimentación. La Fig. 5 indica la frecuencia de menciones que los relatos y narrativas hacen para cada uno de estas categorías. Seguidamente exponemos algunas de estas narrativas que ilustran cada una de las categorías definidas en el análisis del contenido.

\section{a) Razones socioculturales de las} transformaciones en la alimentación

Los relatos detallan dificultades para la libre circulación por las quebradas y lomas de La Calera y regiones aledañas debido a la creciente expansión de la propiedad privada, restringiendo así el acceso de los pobladores de la zona a los diferentes recursos que brinda el Chaco Serrano; como así también la imposibilidad de criar animales, etc. Así comentan:

"no sé si habrá más frutales (membrillos, higos, naranjos), como han cerrado los de Minetti no dejan pasar a nadie" (Pedro O., Villa El Diquecito, III-2017)
Otra de las razones pone de manifiesto el cambio en la calidad y la capacidad nutritiva de los alimentos modernos respecto de los de antaño, como así también el aumento de la industrialización de los mismos, lo que va en desmedro de su calidad alimenticia. Así lo evidencian los siguientes comentarios:

"Las comidas, lo mismo, eran otras comidas que se hacían porque el alimento era distinto al de ahora, al de ahora le sacan hasta el máximo; la mazamorra ya no tiene ni gusto, el maíz viene casi entero, ante venia molido y uno hacía hervir un poco de maíz lo dejaba de la noche que se ablandara un poco, lo dejaba en remojo y al otro día se servía en un... porque nosotros no teníamos cocina nada era un fogón todo a leña, y la dejaba enfriar a la mazamorra y le quedaba espeso ese jugo, quedaba espeso, ahora no, hice la vez pasada porque estuve en Arguello, tengo la casa ahí, y hice mazamorra y es agua nomás no, no rinde, el arroz lo mismo, el arroz uno hierve el arroz y por ahi le sale blando en la punta y adentro sale duro y no hay arroz bueno, no hay, no hay y bueno hay mucha cosa, la polenta es gruesa la que viene ahora, en un minuto y antes 
mi vieja me sabia tener como una hora revolviendo la olla con la polenta y lo que quiera pero era rica, tenía otro sabor pero la de ahora no va, me dan asi de vez en cuando me hacen polenta las chicas las, hijas mías no, no me corre, no porque viene el maiz entero es del maiz colorado e' ahora se vende mucho afuera" (Carlos K., Casa Bamba, XI-2016)

Otros relatos dan cuenta de modalidades diferentes de aprecio por los sabores y gustos entre las distintas generaciones, que ocasionan rechazos en el consumo de alimentos especialmente los del pasado:

-Ha ido cambiando el gusto se han acostumbrado a otros sabores -ahora están acostumbrado a mucho, a muchas cosas que se yo; como ser, la sopa le echan caldo, y ya se hacen su sopa; un caldito, ya está, y uno, no, yo no, yo tengo que echarle carne tengo que echarle verdura sino no, a mí el caldo solo no va ahora ya es moderna la gente le echan un caldito le meten agua hervida y ya está la sopa le echan un fideito chiquito y ya está la sopa. Antes se comían esos pucherazos que se hacían-como ha cambiado -si todo ha cambiado, todo ahora la polenta si no es la polenta de 5 min de 10 min ya no la comen, antes se comía esa otra polenta que venía polenta ahora esa polenta moderna porque es de 10 min 5 min -y no es tan sabrosa - eh noh no tiene casi el gusto de la otra que la otra es de maíz que se yo, pero es rica usted se prepara una fuente de esa con mucho queso mucha salsa una linda salsa y ya está (Catalina C. Villa El Diquecito, XII-2016)

Vemos como los cambios en la alimentación de las nuevas generaciones responden a cambios en los patrones de gusto, estos a su vez, influenciados por los nuevos productos disponibles generando nuevas motivaciones y costumbres alimentarias.

- ¿Hay comidas que hoy se desprecian por alguna razón o de pobre? Y el pobre comía antes toda esas cosas el puchero, la sopa y la mazamorra el locro esas la comían los pobres antes siempre porque no alcanzaba para hacer otra cosa porque usted tenía el zapallo tenía la carne, porque tenía carne sí tenía chancho o tenia que se yo por ahi tenia carnicería que es más barata todo eso pero ahora si no comen asado no comen milanesa no comen bife no, no comen otra cosa; el locro hay veces que alguna le gusta otro no" (Catalina C. Villa El Diquecito, XII-2016)
En el siguiente párrafo se pone de manifiesto nuevas aficiones y gustos por especies y sabores no habituales (malezas comestibles o alimentos como medicinas), que forman parte de saberes adquiridos por otras vías que no son la transmisión oral (consulta a libros), todo esto característico de pobladores neorrurales.

"Si había un libro que me interesó que digo algún día voy a ver si lo leo lo que hizo Nóbile... - ¿De las malezas comestibles? - Eco, digo que será, vos sabes que me gusta un poco eso verlo porque capaz que haya cosa que yo no lo juno y el sí, tiene otro conocimiento, como ser el helecho acá el culandrillo, acá hay pero yo sé que es para los parásitos, y para el reuma y no sé mas... y a mí el título me ha interesado por que capaz nosotros los tenemos como malezas y son buenos, como ser a vos que te dije del cardo... -Y ¿cómo los comes al cardo, al diente de león? - Al diente de león como ensalada, como es amarguita a mí me gusta así amarguita y más porque tiene mucha vitamina c los que han estudiado dicen que tiene mucha vitamina c la leche esa que tiene....ंeste año has comido diente de león? -Sí, si si por año ponele, por año a lo menos serán 4 veces, al menos, es lo menos pero... ¿Y la lengua de vaca igual? -También, eh la lengua de vaca tiene un gustito saladito y es ricasa. - ¿Eso también en ensalada? -Claro, y no se para que será bueno pero es, si es creación algo bueno tiene" (Lalo P., Paraje Boca Dos, XI-2016)

"Las hojas (del cardo) tienen una espina que yo cuando lo como no se desintegra toda y no cualquiera lo va a comer y en ese caso no creo que lo vayan a usar porque cuesta sacar las espinas entonces que opta uno, ahi lo dejas no lo comes nada pero cuando vos lo tratas como a un remedio entonces decís no yo lo voy a comer, entonces aunque sea un poco así medio no tan agradable que te hinca un poquito yo lo como igual...claro uno lo tiene que tomar como un remedio, yo siempre les explico a mis hijos, ¿todos los remedios son ricos? no hay algunos remedios que son feos y porque lo toma y bueno porque son remedios y bueno ese ejemplo lo tenés que hacer con hay cosas que son buenas para la salud aunque sean desagradables de sabor, y entonces las espinitas por ahi molestan un poco pero vos comelo, que es para la salud, ahora si vos encontrás un cardo viejo con la espina dura no ese no porque no se va a desintegrar... uno tiene que tener un criterio. Siempre lo uso así como 
en bife a la criolla como verdura para los bifes a la criolla" (Lalo P., Paraje Boca Dos, XI-2016)

En este punto, se dejan entrever cambios en el estilo de vida (costumbres, economía doméstica), en los valores éticos y de sociabilidad, en las diferencias entre la actualidad y los tiempos pretéritos, y cómo estos cambios moldearon sus costumbres y valores.

“...Todo se movía por el ferrocarril, antes no habia ruta, esta ruta llega hasta el 14 más o menos, ahi la cortaban... Y que... pasó una señora de Santa Fe y yo vendía tortilla, vendía pan, empecé a vender tortilla a los chelqueros, vino una creciente grande del 39 que tapo toda la estación y trajeron una cuadrilla de, de indigentes, eran los chelqueros y yo le vendía tortilla a ellos y llevaba, cuando mi vieja estaba en la casa, le llevaba la ropa de alguno para lavar y así vivíamos y juntábamos hongos en verano" (Carlos K., Casa Bamba, XI-2016)

(Al hongo de coco) "lo juntaba a la tarde en la bolsa, porque eran bolsa de arpillera abierta. $Y$ ahi lo secaba yo arriba del techo de la casa, mi vieja preparaba alguna comida, algo a la ligera, huevo, cebolla algo así preparaba y volvía a salir al campo, ahi no sentíamos calor, ni sol, ni nada y andábamos juntando hongos. Una vuelta junte 7 bolsas de harina, porque antes venia la harina de 70 kilos, eran unas bolsas hermosas, tenia sabanas, hasta eso hicimos, sabana de bolsa de harina y de esto, de corsemar, que venían antes, porque ahora es de papel, y hasta eso, jeje..." (Carlos K., Casa Bamba, XI-2016)

- ¿Y los vendian, vendian hongos? "-Claro, venían los compradores, venían en tren los compradores, pagaban un peso el kilo, el blanco blanco pagaban más de un peso, uno veinte creo, no recuerdo bien, después el morocho tenía otro precio; y el negro, ese ya demoraba en secarse porque llovía mucho, llovía y salía el sol, eh y el vapor, ahi nomás habia que rajar al campo porque con el vapor que se juntaba de la tierra mojada empezaban a salir los hongos, y eh mierda, en un ratito traíamos y sabían estar las piezas llenas de hongos en las cama, habian estado los patrones antes y quedaron las cama ahi y eh poníamos en el suelo los elásticos y hongo que eran medio pasado, ya medio aguachento lo tirábamos al arroyo y lo reemplazábamos por uno nuevo y habia que hacer así, porque tanto que era la cantidad que habia, que salia y lo juntábamos habia que aprovechar" (Carlos K., Casa Bamba, XI-2016)

En algunos casos consumir frutos del monte era un ejercicio practicado en la infancia a modo de juego o como parte de sus andanzas, así lo muestran los siguientes relatos:

"Nosotros sabíamos comer cuando éramos chicos el frutito (higuerilla), todo alrededor comíamos, todos los pelitos, lo rojo, eso comíamos y era medio dulzón, teníamos... 15 años”. -¿Quién te enseño eso? "-No, no se, era cuestión de todos los chicos, claro, porque a veces estaba comiendo uno, che... este y vos probabas y si te copaba, le daba, pero de ahí no sé..." (Lalo P., Paraje Boca Dos, XI-2016)

Otros alimentos o pautas de alimentación están asociados a cuestiones de género por considerarlas estrechamente relacionadas con el ámbito femenino y el rol de la mujer o de la madre en la familia:

"El tasi no, ese es para las mujeres para que den leche para los niños"-¿ ¿l fruto no lo comió nunca? - "no, ese lo comen las mujeres" (Carlos F., Villa El Diquecito, XI-2016)

Asimismo documentamos relatos acerca del posicionamiento sobre la mujer y su rol central respecto de la labor culinaria y la crianza en el hogar; responsable de la comida que se servía o debería servir también en tiempos actuales.

"yo los mios son grandotes y les gusta comer, ellos te comen a las doce y a la noche, así sea un guisito carrero, lo que sea, pero ellos comen viste y bueno, y ahora nomas estaba pensando qué voy a hacer" - ¿y qué más ve de las generaciones jóvenes a la infancia de uno...? "-Y bueno, los chicos elijen ahora la pizza, el lomito, un bife con ensalada, la milanesita, todo como chatarra, no hay mucha verdura, en cambio mi mamá hacía a lo mejor un puchero con mucha verdura, hacia un purecito y la carne y después tomaba la sopa" (Mirta C.; La Mesada, XII-2016)

"todo esto de las rotiserías y comidas rápidas distraen las amas de casa y no cocinan, se olvidaron de los guisos, locro, tortillas. No me gusta el locro y no lo probaron nunca, igual que la mazamorra, buseca, ahora todo sándwich. Acá 
siempre mazamorra con leche, locro, empanadilla de dulce de batata, arrope de tuna, miel, calabazas, pan casero, tortilla al rescoldo y pan con queso..." (Jorge L., Paraje Boca Dos, XII-2016)

El cambio en los aspectos éticos y de sociabilidad se hace sentir en los siguientes testimonios:

"el piquillín viene el negro el piquillín naranja y un colorado, que rico el piquillín negro grande sabe haber mucho para allá para la sierra ahora hace como 4 o 5 años que no como que no voy para allá..., bajaba del caballo me sabia bañar en el arroyo iqué fresquita esa agua! pero ahora no se puede ni bajar del caballo, tengo miedo hay tanto sinvergüenza, ehh no se puede ahi roban los caballos..." (Elvira R., Villa El Diquecito, XII-2016)

La economía doméstica se veía enriquecida con el sustento de los animales de granja y la chacra o huerto, acompañado de frutales. El tren de las Sierras también formaba parte del día a día de los lugareños, ya que recurrían a él para la venta de diversos productos manufacturados o hierbas recolectadas de las sierras:

"sabiamos vender la bolsa (de peperina) en Saldán, cuando tenían ahi en la fábrica de peperina y ahí venían a buscarnos acá a la redonda, a la peperina, la vendíamos por bolsa pero verde y te vendíamos molle, la hoja del molle, la hoja del coco, porque tenía mucho alcohol eso, eh pero éramos chico, cuanto años tendríamos 10 años, 12 años y esas cosas hacíamos" (Carlos K., Casa Bamba, XI-2016)

"Antes se cosechaba mucho no es como ahora, ahora nadie pone una planta de verdura" (Catalina C., Va. El Diquecito, XII-2016)

- ¿Y tenían huerta o chacrita? "-Nosotros antes solíamos tener choclo, teníamos batata, teníamos maní, en la arena salía un mani de lindo, grande, eh acelga, lechuga, rabanito todas esas cosas se tenía antes, perejil porque allá era una chacra grande era, allá donde vive mi hermana para arriba, ahora han hecho casa todo eso, todo eso era una chacra, va chacra, que teníamos para sembrar...zapallito de tronco igual que las remolachas, había unas remolachas grandisimas porque se ve que la arena no apretaba mucho, se criaban, zapallo grande, zapallo chico de todo teníamos ahi” (Catalina C. Villa El Diquecito, XII-2016)

Si bien la mayoría de los relatos dan cuenta que los tiempos pasados fueron mejores en materia de alimentación, sin embargo, en otros se rememora las carencias que acompañaban a la cotidianeidad de la gente y el rol que allí tenían las plantas silvestres:

“... habia hambre antes, ahora no, ahora tenes hambre, sali ahi con un paquete de peperina a vender o sea con cualquier cosa, ahora el que tiene hambre es porque no tiene idea o no quiere hacer nada, pero antes no habia que comer, antes no había ni yerba, no había... era dificil antes entonces era a lo que se podía hacer y bueno una de las cosas que se morfaba era la acacia" (Lalo P., Paraje Boca Dos, XI-2016)

Otro de los factores socioculturales es la influencia de los medios de comunicación, la publicidad de las industrias, dirigiendo la demanda por medio de la oferta de productos de rápida cocción o ya listos para consumir:

"Cambió, porque es parte del modelo, de la seguridad, de la comida elaborada, de la falta de educación; y lo interesante es esta corriente de retomar, o si tengo suerte de cruzarme o gente o cursos de plantas comestibles del patio y la revalorización. De la teoría a la práctica hay un paso importante, y la estructura te limita y te pone freno, pero con la práctica se cambió, y el tema del miedo que también se vendió, la comida viene en paquete para que sea segura. (Me gusta) todo lo más casero que se pueda, hay una resistencia, y está tan arraigado y la falta de tiempo, ...todo parte del sistema es venderte esa inseguridad, esa falta de confianza en los conocimientos ancestrales" (Paula A., El Diquecito, III-2017)

Algunos relatos dan cuenta de la influencia de las prácticas asistenciales en la alimentación en la dieta escolar, tal como lo indica el siguiente relato de la cocinera de una de las escuelas rurales que se provee de los menús del Paicor (Programa de Asistencia Integral Córdoba):

"el locro está (en el menú del Paicor) pero en el de invierno, al final en el menú de emergencia pero yo lo hago pero lo único que no le pongo es, porque dice de emergencia y también hay que 
hacerlo con carne sola, no con ... chorizo colorado, tripa gorda" - ¿eso le piden en el menú que sea con carne sola? "-Que sea con carne sola, yo le pongo bastante carne, no sabe cómo lo comen..., pimienta, pimienta no uso, no, no permiten" - ¿por qué no, por alérgicos? "-no sé, no porque es picante y el chiquito no lo come, yo pienso que es eso" - ¿y la mazamorra está en el menú que viene, el menú escolar? "-no, por eso te digo que no, salvo que me consiga, por ahi pido para ponerle para el locro y a lo mejor me queda una bolsita..." (Mirta C., La Mesada, XII-2016)

Otro de las razones socioculturales de transformación de la alimentación, han sido los cambios culturales, el desconocimiento y la pérdida en la transmisión de saberes.

"Esto por ahi a veces es extraño lo que coso pero resulta que es la realidad ahora los chicos hoy acá capaz que vos, salteño, capaz que todavía allá coman algarroba acá ni... vos pasas por el centro de Calera saben caer las algarrobas riquísimas que caen ahi, en el medio donde hay un bar, yo sé juntar ahi para comer porque son grandes carnosas bien hermosa y pero la gente ni, ni se dan cuenta que eso es para comer..." (Lalo P., Paraje Boca Dos, XI-2016)

\section{b) Razones ambientales del cambio cultural}

Uno de las razones ambientales son las dificultades para recolección y hallazgo de algunas especies como el hongo de coco, hinojo y albarillo.

"Si los hongos (de coco) íbamos a buscar los hongos silvestres íbamos a buscar al campo, y yo deje de ir pero algo queda, antes se especializaba uno y estaba en el tiempo se daba cuenta por la luna por el sol por el calor por la lluvia uno se daba cuenta y más los viejos, la gente grande te indicaba mejor, te decian vayan que es el tiempo del hongo y ya nos mandaban a buscar hongos y seguro que habian encontrábamos ahora casi se ha perdido eso entonces ahora la gente casi ya no sabe cuándo es el tiempo yo mismo no me acuerdo bien cuando es el tiempo, claro yo me acuerdo que era después de la lluvia y habia que tener calor y la luna que alumbre la luna y el sol, claro habia varias cosas de esas que iban juntas, y nos sabían decir que tratáramos de no arrancarlo, porque ahi quedaban las semillas decían, no sé cómo sería pero dicen que quedaba la semilla, que dejáramos los pies" (Lalo P., Paraje Boca Dos, XI-2016)
“El hinojo ya se está perdiendo ya es el mismo que el de la verdulería pero ahora lo cultivan y antes era espontaneo nacía en el campo en cambio ahora no sé qué bicho es el que lo comió porque ya no queda" (Lalo P., Paraje Boca Dos, XI-2016)

"El albarillo sí, pero es muy raro que haya una planta por acá muy raro; hay plantas ahi en esas canteras pero no dan-hace cuanto -si no muchos años antes, porque ahora hay esa planta yo la conozco a esa planta porque es parecida a la planta del damasco pero no, no dan fruto" (Elvira R., Villa El Diquecito, XII-2016)

Otras razones son los incendios, deforestación y pérdida del monte nativo silvestre.

"Hay poco coco en la sierra ha habido dos incendios muy muy grandes y el coco es un árbol de mucha agua que a mí me están naciendo un acá que... que los estoy cuidando pobrecitos porque este, no hay mirá que yo camino mucho por ahí en la sierra y no no se ven, claro por su contextura viste el árbol necesita mucha agua y eso y se secan mucho naturalmente ves? empiezan de chiquitos y no llegan a grandes" (Dario H., Paraje Casa Bamba, XII-2016)

"Antes habia muchos algarrobos en la zona, pero han venido por encargo para que corten" (Pedro O., Villa El Diquecito, III-2017)

Las interacciones perjudiciales con los animales resultan también influyentes, tal como lo muestra el siguiente relato.

"le tenés que preguntar a las loras porque no dejan nada, hay plantitas acá de chañar tengo unas que he dejado grande, pero las loras no te lo dejan, cuando éramos chicos comíamos todo el tiempo íbamos al campo a comer... yo comía el fruto" (Lalo P., Paraje Boca Dos, XI-2016)

Los cambios ambientales y estacionales o en el régimen hídrico (sequías, inundaciones, etc).

"El (hongo) de coco si después vino una sequía muy grande, las majada se comieron las cáscara del coco y se secó, ahora no hay más majada, está volviendo el coco pero ya los hongos no creo que vuelvan a lo mejor para enero sale alguno pero hay mucho yuyo para ahora ir a buscar, acá sabiamos juntar hongo toda esa loma hay porque antes no estaba la ruta empezábamos del rio para arriba", (Carlos K., Casa Bamba, XI-2016) 
A. Fernández \& G. J. Martínez, Plantas alimenticias en la ruralidad de Córdoba

Tabla 2. Comparación diacrónica entre los tiempos del pasado y del presente.

Table 2. Diachronic comparison between the times of the past and the present.

Tiempos, gente y comidas del pasado

Gente era humilde, muy dada, conversadora, sociable Gente poco sociable

No tenían tiempo para otras cosas, tiempos de mucho Juventud tiene tiempo para diversión "está en trabajo, y poco descanso ni aún los domingos

Tiempos muy tranquilos. Se buscaba un trabajo o changa

En Semana Santa o Viernes Santo se respetaba, no se faenaba ni comía carne

Niños obligados a comer más allá del gusto, para estar fuertes para trabajar. Comían de todo según se les exigía

Era muy distinta la vida de antes a la de ahora

Eran otras comidas, porque el alimento era distinto

Se carneaba, no había heladera, se tenía fiambrera

Antes hacía frío en la zona

La fruta "no se embichaba" (ej. algarroba)

Antes había mucha algarroba

Había hongos "hasta debajo de la cama"

Antes se trabajaba mejor

Los alimentos eran más nutritivos

Antes se peleaban para vender la grasa

Antes había animales (vizcachas, etc.)

Antes había mazamorra, locro, polenta, arroz con leche, harina, polentas lentas, mazamorra con leche; eso era lo de antes. Sastaca, charqui, quesos, quesillos. Sopa con carne, verduras, "pucherazos"

Antes se cocinaba al fuego nomás

Antes todo se hacía a mano

Los más grandes aprendieron algo, todavía están rescatados

Ingredientes tradicionales: maíz, poroto, zapallos

Antes era habitual caminar por las montañas

\section{Tiempos, gente y comidas del presente} otra"

Tiempo de baile, drogas, ausencia de tranquilidad, no se buscan trabajos

No se consideran estos recaudos para Semana Santa

Niños delicados, no valoran nada; deciden comer en función del gusto

Todo está caro ahora, no como antes

Ahora le sacan "hasta el máximo" al alimento

Ahora se está en el "progreso", era muy distinta la vida de antes y de ahora

Ahora no hay invierno, "hace una pila de años"

La fruta de hoy "se embicha"

Ahora no cuaja la algarroba, y está más seca la vaina

Dificultad para el hallazgo de hongos

Ahora así nomás hacen las cosas a la buena de Dios

Ahora una comida famosa es la chatarra

Ahora hay tripa de plástico, los chorizos no sirven

Ahora mataron todo (animales)

Ahora viene todo hecho, es más fácil comprarlo o todo es artificial. Milanesas, pizzas, polentas rápidas, sopas en calditos, pata flambeadas. La nueva generación "no le da bola" todo debe ser envasado y rápido

Ahora en tiempos modernos tienen gas

Ahora todo viene hecho

La generación que sigue es más "todo a lo hecho"

Nuevas plantas (malezas comestibles): diente de león, amor seco, lengua de vaca

Ahora no se camina por la montaña
Otros de los motivos influyentes son la pérdida de aptitud y calidad del recurso natural.

"Uhh antes habia muy mucha algarroba, ahora no, cuando está la planta, está en flor empieza a llover y se lava queda un poco de algarroba pero ya no, se reseca mucho, para mí que es el sol eh el que seca mucho la vaina, antes no, antes era más jugosa" (Carlos K., Casa Bamba, XI-2016)

"Higueras, bueno hay negra, negra y una media blanca hay todavía alguna, después yo llevé de Córdoba otra higuera pero no me acuerdo el nombre pero eran unos higos asi de grande y el año pasado, el anteaño pasado, el otro año de acá a tres años se 
embichaban no podía comer porque se embichaban y después cuando cambio el clima y el sol se ardía... estaban seco adentro y ahi ya no pude, después el anteaño pasado fui a buscar otra higuera en otra gente que vivian antes que dejaron las plantas, estaban secas así que ahora no ya no sé" (Carlos K., Casa Bamba, XI-2016)

Sintesis de la mirada diacrónica y del cambio cultural en materia de alimentación

En la Tabla 2 se resumen las principales diferencias que se visibilizan en las narrativas y que surgen de la comparación entre los tiempos, la gente y comida del pasado con las del presente.

\section{Discusión}

$\mathrm{Si}$ atendemos a las cantidades de especies y aplicaciones alimenticias documentadas para La Calera, superan a las de trabajos previamente realizados en poblaciones campesinas de Córdoba (Arias Toledo et al., $2007 \mathrm{a}, \mathrm{b})$ quienes relevaron el uso de $15 \mathrm{y}$ 25 especies comestibles para dos regiones de la provincia de Córdoba, el Chaco Árido y el Chaco Serrano respectivamente. Aunque Arias Toledo et al. (2007b) no detalla la totalidad de las especies comestibles del Chaco Serrano, existen coincidencias en las especies más comúnmente utilizadas y mencionadas, siendo las más frecuentes el piquillín (Condalia spp.), algarrobo (Prosopis spp.) chañar (Geoffroea decorticans) y granadilla o pasionaria (Passiflora caerulea). Asimismo Trillo et al. (2014) aporta 14 especies de uso comestible para el Departamento Minas, en la región árida del Chaco Seco, buena parte de ellas incluidas en nuestro listado, (se citan solas en este trabajo Bouganvillea stipitata, Prosopis torquata, Prosopis chilensis, Tillandsia duratii y Vallesia glabra). Mientras el trabajo de Saur Palmieri et al. (2018) menciona 20 frutos para el Cerro Colorado en la región del Chaco Serrano, con diversas cactáceas que no están contempladas entre los calerenses (Cleistocactus baumannii, Harrisia pomanensis, Cereus forbesii, Gymnocalycium schickendantzii y Stetsonia coryne). En contraste, otros trabajos con poblaciones criollas en el Gran Chaco Semiárido, como el de Scarpa (2012) dan cuenta de un número bastante superior al aquí documentado, alcanzando las 86 especies alimenticias y más de 180 usos entre nativas y exóticas. Encabeza el listado el maíz (Zea mays), especie que por no aparecer directamente en nuestras primeras entrevistas no fue incluido en el checklist de las encuestas, pero no por ello deja de ser relevante, especialmente si atendemos al énfasis con el que se mencionan preparados como la mazamorra o el locro. Otra especie en la que se observa coincidencia es en el algarrobo (Prosopis alba). Un aspecto en el que se diferencia el destino de las plantas alimenticias en ambos grupos culturales, es el consumo directo de frutos silvestres durante las andanzas al monte a modo de tentempié, lo que resulta habitual para este grupo de criollos formoseños y no tanto para estos pobladores cordobeses entre los cuales esto parece haber sido más común en el pasado.

Por otra parte se observa también una menor cantidad de especies consumidas con respecto a la población criolla en el noroeste de La Pampa (provincia vecina a Córdoba) cuya alimentación incluye 62 taxones comestibles aunque esta vez abarcando las verduras de huerta y chacra (Muiño, 2012a, b), las que no fueron contadas en la presente investigación.

Entre los frutos silvestres de las sierras de Córdoba, aquéllos que resultan más comúnmente usados en otras regiones son la algarroba (Prosopis alba), el chañar (Geoffroea decorticans) y el mistol (Ziziphus mistol); aunque este último está casi ausente en el área de estudio, sin embargo forma parte de los recursos que circulan de una región a otra. En Córdoba se reconoce especialmente su consumo directo o la elaboración de harinas para el caso de algarrobo y mistol, así como productos derivados de los mismos (arropes y jaleas). Por el contrario las bebidas como alojas (para el caso del molle, algarrobo y piquillín) sólo han quedado en la memoria de algunos informantes más ancianos y en su mayoría, los entrevistados de este trabajo no han llegado a probarlas. También resultaron especies importantes por su cantidad de usos el hinojo (Foeniculum vulgare), la higuera (Ficus carica) y el durazno (Prunus persica). 
En lo que concierne al cambio en materia de alimentación, se visibilizan particularmente las razones socioculturales relacionadas a transformaciones en el estilo de vida. La creciente pérdida de numerosas prácticas y conocimientos del consumo de algunas especies, la pérdida del control y contacto con el entorno natural y cultural, la erradicación de los pueblos de sus territorios originales (llevándolos a habitar territorios más degradados), hace que sus conocimientos tradicionales se vuelvan menos relevantes. Se observa en resumen para el área de estudio recetarios cada vez menos diversificados, pérdida de ingredientes y del uso de cultígenos tradicionales en la culinaria doméstica (maíces, zapallos, batatas, y sus recetas: locros, mazamorras, charquis). A pesar de esto, ocurre aún la transmisión oral de recetas presentes en la memoria de los informantes de mayor edad. Los relatos de los calerenses dan cuenta que para las generaciones mayores, la comida involucra los sabores, las propiedades medicinales que pueden tener, y a la vez conciben a la alimentación como parte de un "buen vivir" (Delgado \& Delgado, 2014). Por el contrario, los mayores perciben que, para las nuevas generaciones, la nutrición apunta a satisfacer una necesidad en forma inmediata y con alimentos de fácil y rápida preparación, reemplazando así los tradicionales recetarios criollos y produciéndose cambios en la gramática culinaria. Por su parte, aunque con menor énfasis en los relatos, documentamos razones ambientales vinculadas al cambio cultural, tales como incendios, deforestación y pérdida del monte nativo, cambios en el régimen hídrico, en la pérdida de aptitud y calidad del recurso natural, y dificultades para recolección y hallazgo de algunas especies.

Una gran cantidad de prácticas de cocina, recetas y platos tradicionales compilados en este trabajo coinciden con el inventario realizado por Grimaut (2011) para el folklore de la comida cordobesa de la Córdoba de mediados del siglo pasado, al rescatar comidas como el locro, puchero, asado, carbonada, chicharrón, caldo, caldo de patas, morcilla, empanadas, mazamorra, humita, chanfaina, entre otras. También los dulces como alfajores, bizcochos, tabletas, chancacas, arropes y jaleas presentes en el pasado cordobés, se reproducen en algunos casos en la población rural calerense. De manera similar Remedi (1997), señala que la cocina criolla de comienzos de siglo XX en Córdoba se destacaban como comida típica por su incorporación frecuente a la dieta cotidiana la carne vacuna, el maíz (solo, hervido, asado o como ingredientes en comidas), la grasa de vaca, quesillos, zapallo, berro, lechuga, cebolla, ajo, duraznos, sandías, melones, pasas de uva y de higo, yerba mate y azúcar. Asimismo refieren una tendencia de la población criolla a endulzar sus platos típicos, sin desechar el uso de los condimentos como ají, orégano, laurel, pimienta, pimentón, comino, clavo de olor y canela, aspecto que también se observa en los platos y recetas aquí documentados. Muchos de estos preparados e ingredientes también fueron evocados en las entrevistas y narrativas, como se observa en el listado de comidas de La Calera, dando cuenta de la conservación aunque más no fuera en el plano del conocimiento de un folklore alimenticio entre los criollos de mayor edad de nuestra región de estudio. Contrasta esto con las observaciones de Arias Toledo et al. (2017b) quienes señalan la no existencia de diferencias significativas en el conocimiento entre grupos de edades.

Por otra parte, la articulación y circulación a través de los circuitos de alimentos que documentamos en las narrativas y que se dan especialmente con la cocina criolla del noroeste cordobés pueden interpretarse mejor a la luz de las observaciones realizadas por Remedi (1997: 104). Este autor plantea que la cocina criolla se hallaba extendida en todo el espacio cordobés, pero era mucho más notoria en la zona noroeste de la provincia. Señala en este sentido que "esta región representó un refugio seguro para la cocina criolla frente a la creciente difusión geográfica y social de las cocinas étnicas provenientes especialmente de las migraciones italianas y españolas".

En lo que concierne a la circulación de la información y transmisión de las recetas de alimentos se realiza según refieren los entrevistados calerenses, por lo general en forma oral o práctica, y, a excepción de las malezas comestibles, no se realiza por medio de libros de recetas o literatura culinaria. 
De acuerdo con Remedi (1997: 110), el influjo español secular y el de la corriente inmigratoria española más recientes se hizo sentir en la cocina criolla de sectores populares, en platos tales como el puchero, la chanfaina, la carbonada, la morcilla, y en verduras tales como cebolla y ajo, también en condimentos como azafrán y pimentón que forman parte del relleno de empanadas. Asimismo en el gusto por lo dulce y elaboraciones como alfajores, bizcochos, pasteles, arroz con leche y canela, entre otros. En ciertos casos "la adopción de elementos de la gramática culinaria española por parte de la población nativa conllevó un proceso de homologación cultural, por intermedio del cual se incorporaban ciertos alimentos o preparaciones pero de acuerdo con determinados patrones de consumo peculiares de aquella". Así, se sustituye el puchero de carne de aves de corral en su versión española, por el de carne vacuna.

En relación con las carnes vemos que son muchos los preparados culinarios que hacen uso de la misma, corroborando la sentencia de Alvarez \& Pinotti (2000) cuando refieren que "comida, desde el siglo XVI, siempre ha sido carne y algún complemento" o bien que "la tradición de la carne es tan fuerte que aún hoy celebrar es hacer un asado". Estos mismos autores sugieren que los inmigrantes fueron alcanzados por la "pasión carnívora" de la cocina criolla, ya que su dieta era esencialmente vegetariana y hasta el momento de contacto apenas consumían carnes rojas, artículo central de los nativos. En contraste el criollo nativo de sectores populares no era afecto a las verduras, mirando con recelos algunos productos del mercado local (ej. zanahoria, berenjena, remolacha) que eran calificadas como "comidas de gringos" prefiriendo zapallo, ajo, cebolla, berro, ajíes, tomates, papas y batatas. Las verduras de quinta, por su parte, no formaron parte de la cocina tradicional hasta que fueron introducidas por los nuevos inmigrantes entre fines del siglo XIX y comienzos del siglo XX. Sin embargo, las verduras no fueron estimadas como un alimento completo, excepto para los enfermos; siempre se integraron como accesorios al plato principal, la carne vacuna. "La verdura siempre e invariablemente será equiparada a un mero complemento" (Alvarez \&
Pinotti, 2000). En contraste en relatos calerenses aparecen como relevantes tanto los preparados con carne, como los elaborados con productos de la chacra tal como se observa en el listado de comidas surgidas en nuestras entrevistas (Anexo 1). En los relatos recogidos, en lo que concierne a los momentos festivos, se usa sobre todo zapallo y maíz, y también batata (ej. batata con leche); en contadas ocasiones por ejemplo para empanadas de vigilia la espinaca, pero no están las verduras de quinta como parte central del menú.

En el listado de recetas obtuvimos referencia a la elaboración de nueve panificados. Remedi (1995) refiere para la alimentación de comienzos del siglo XX en Córdoba, que el pan "era un alimento del inmigrante europeo por excelencia que fue incorporándose al consumo de la población nativa". En los comienzos era escaso el aprecio que tenían los criollos de este producto, y demostraba cierta resistencia ofreciendo otros productos para complementar o acompañar el consumo de carne o de locro. "En la gramática culinaria del nativo, el sanco enfriado, el ancua, la mazamorra, y el maíz en grano hervido - mote cordobés- junto con el zapallo -fresco, asado, hervido o desecado- representaban el papel que el inmigrante extranjero atribuía al pan". "La oposición "nativo/extranjero" era en cierta medida, en términos alimentarios, una oposición maíz/trigo". Al presente esta oposición no se observa, y el pan ocupa un lugar protagónico en la mesa cotidiana, y como vimos existe todavía en la cultura calerense la elaboración y venta de panes caseros en diferentes versiones no sólo para consumo doméstico sino para su comercialización, aunque en algunos casos como el pan de semita ya no se elaboran.

Con respecto a las observaciones vinculadas con la construcción de género en la alimentación del pasado y actual, Alvarez \& Pinotti (2000), dan cuenta de la persistencia del rol femenino en el trabajo culinario desde la época colonial. También en las representaciones tradicionales que surgieron en las narrativas, la comida aparece como alimentos consumidos en el hogar y cocinados por la madre de familia. A pesar de esto, los valores cuantitativos ponen de manifiesto un mayor conocimiento y uso de plantas alimenticias por parte de los hombres en relación con las mujeres, diferenciándose de la 
tendencia señalada por Arias Toledo et al. (2007a, b) para las regiones de Chaco Árido y Serrano, quienes no hallaron diferencias significativas, aunque con valores de conocimiento levemente superiores para las mujeres.

En relación con las nuevas aficiones como el consumo de malezas comestibles caben algunas consideraciones. En el caso de este trabajo en La Calera, las especies o malezas comestibles más señaladas fueron el diente de león, la lengua de vaca, el amor seco, la verdolaga, y otros similares a los reseñados para otras poblaciones que también las consumen (Ladio, 2005). En su mayoría son mencionadas por pobladores en busca de nuevos conocimientos o de los antiguos que recordaban a sus madres preparando platos como torrejas o ensaladas con dichas especies. En este aspecto participan en la revalorización y recuperación de saberes del pasado, aparte de la transmisión oral, otras fuentes como los medios de comunicación (radios, libros, redes sociales, etc).

\section{Conclusiones}

En lo que concierne al conocimiento de las especies alimenticias, éste todavía perdura entre los pobladores, aunque su uso se encuentra en franco retroceso. Se destacan por su cantidad de usos el hinojo (Foeniculum vulgare), chañar (Geoffroea decorticans), algarrobo (Prosopis alba), higuera (Ficus carica) y durazno (Prunus persica). Entre las especies y usos conocidos por todos los entrevistados encontramos los frutos de algarrobo (Prosopis alba), chañar (Geoffroea decorticans), mora (Morus alba), higuera (Ficus carica), tuna (Opuntia ficus-indica), uvita del campo (Salpichroa origanifolia) y berro (Nasturtium officinale); resultan también muy conocidos el nogal (Juglans regia), tala (Celtis ehrenbergiana), mistol (Sarcomphalus mistol) y piquillín (Condalia spp.). Asimismo, se colecta y menciona por primera vez para Córdoba la presencia y uso alimenticio de los frutos del jínjoli (Ziziphus jujuba Mill., Rhamnaceae) cultivado en el ámbito domiciliario de algunos pobladores calerenses.

Por su parte, la mirada diacrónica arrojó diversidad de factores o razones culturales y ambientales asociado a las transformaciones en la alimentación y culinaria, siendo los de mayor peso y frecuencia de mención el estilo de vida y los cambios en el patrón del gusto, nuevas aficiones y desplazamientos en los usos.

En la ruralidad cordobesa (para el caso La Calera) han existido y aún existen relictos de saberes locales que pueden considerarse patrimonio biocultural, lo que hace posible sostener algunos rasgos de seguridad alimentaria con soberanía, aunque ésta en general se halla empobrecida por los cambios culturales en materia de alimentación y del uso decreciente de plantas comestibles en ambientes cada vez más deteriorados.

Finalmente, se observa una alimentación que recurre cada vez menos al uso de plantas silvestres comestibles, y una cocina más dependiente de insumos externos y de productos elaborados. Esta tendencia muestra una mayor desapropiación y desvinculación del lugareño con su entorno rural próximo, siendo cada vez menos común la búsqueda y recolección de especies comestibles y la preparación de comidas con estos ingredientes.

La recuperación de saberes locales en alimentación, el registro de usos pasados de alimentos como los que aquí se señalan contribuirá al sostenimiento de la diversidad biológica (por la variedad de especies utilizadas) y con ella la diversidad cultural (núcleos poblacionales y grupos de edades presionados en sus saberes como los aquí abordados).

\section{Agradecimientos}

A los pobladores de La Calera por su apertura y confianza con nuestra labor de investigación. A Fernando Zamudio por su asesoramiento en etnocategorías. Al CONICET y a la ANPCYT (PICT 1633 y 1001) por el financiamiento para llevar a cabo este estudio.

\section{Bibliografía}

AGUIRRE, P. 2004. Ricos flacos y gordos pobres. La alimentación en crisis. Edit. Capital Intelectual. Buenos Aires.

AGUIRRE, P. 2007. Qué Puede Decirnos una Antropóloga sobre Alimentación. Hablando sobre Gustos, Cuerpos, Mercados y Genes. Disponible en http://www.fac.org. ar/qcvc/llave/c027e/aguirrep.php. Activo agosto 2017. 
ALBUQUERQUE, U. P., R. F. P. LUCENA \& N. L. ALENCAR. 2010. Métodos e técnicas para a coleta de dados etnobiologicos. En ALBUQUERQUE, U. P., R. F. P. LUCENA \& L. V. F. CUNHA (orgs.), Métodos e técnicas na pesquisa etnobiologica e etnoecologica, pp. 39-63. Editora NUPEEA, Recife.

ALEXIADES, M. N. 1996. Standard techniques for collecting and preparing herbarium species. En ALEXIADES, M. N. (ed.), Selected guidelines for ethnobotanical research: A field manual. New York Botanical Garden, pp. 99-126. Bronx, New York.

ALVAREZ, M. \& L. C. PINOTTI. 1997. Procesos socioculturales y alimentación. Ed. del Sol, Buenos Aires.

ALVAREZ, M. \& L. C. PINOTTI. 2000. A la mesa. Ritos y retos de la alimentación argentina. Ediciones Grijalbo, Buenos Aires

ANDERSON, E. N., D. M. PEARSALL, E. S. HUNN \& N. J. TURNER. 2011. Ethnobiology. Wiley Blackwell, USA.

ARENAS, P. 2003. Etnografía y alimentación entre los Toba Nachilamole\#ek y Wichí-Lhuku'tas del Chaco Central (Argentina). Ed. El autor, Buenos Aires.

ARIAS TOLEDO, B., S. COLANTONIO \& L. GALETTO. 2007a. Knowledge and use of edible and medicinal plants in two populations from the Chaco Forest, Cordoba Province, Argentina. J. Ethnobiol. 27: 218-232.

ARIAS TOLEDO, B., L. GALETTO \& S. COLANTONIO. 2007b. Uso de plantas medicinales y alimenticias según características socioculturales en Villa Los Aromos (Córdoba, Argentina). Kurtziana 33: 79- 88.

BERNARD, H. R. 2006. Research methods in anthropology: qualitative and quantitative approaches. Library of Congress, USA.

CABRERA, A. L. 1994. Regiones fitogeográficas argentinas. Enciclopedia Argentina de Agricultura y Jardinería. Tomo II (I) Acme, Buenos Aires.

Censo Provincial de Población. 2010. DIRECCIÓN GENERAL DE ESTADÍSTICA Y CENSOS DIRECCIÓN DE ESTADÍSTICAS SOCIODEMOGRÁFICAS.

DELGADO, F. B. \& M. A. DELGADO. 2014. Vivir y comer bien en los Andes Bolivianos. Aportes de los sistemas agroalimentarios y las estrategias de vida de las naciones indígena originario campesinas a las políticas de seguridad y soberanía alimentaria. Plural Editores, La Paz, Bolivia.

FAO (Food and Agriculture Organization). 1996. Declaración de Roma sobre la Seguridad Alimentaria Mundial. Cumbre Mundial sobre la Alimentación, 13 al 16 de noviembre. Roma (disponible en http://www.fao.org/docrep/003/ w3613s/w3613s00.htm).
GIORGIS, M. A., A. CINGOLANI, F. CHIARINI, J. CHIAPELLA, G. BARBOZA, L. ARIZA ESPINAR, R. MORERO, D. GURVICH, P. TECCO, R. SUBILS \& M. CABIDO. 2011. Composición florística del Bosque Chaqueño Serrano de la provincia de Córdoba, Argentina. Kurtziana 36: 9-43.

GREEN, E. C. 2001. Can Qualitative research produce reliable quantitative findings? Field Method. 13: 3-19.

GRIMAUT, A. 2011. Comidas cordobesas de antes. Buena Vista Ed., Córdoba.

GRIMAUT, A. 2012. Lo que quedó en el tintero. Buena Vista Ed., Córdoba.

GUBER, R. 2005. El salvaje metropolitano, Reconstrucción del conocimiento social en el trabajo de campo. Paidós, Buenos Aires.

KARLIN, M. S., C. SCHNEIDER, S. RUFINI, J. BERNASCONI, R. ACCIETTO, U. KARLIN \& Y. FERREYRA. 2014. Caracterización florística de la Reserva Natural Militar Estancia La Calera.Nature and Conservation. Aquidaba 7: 6-18 DOI http:// dx.doi.org/10.6008/SPC2318-2881.2014.001.0001

LADIO, A. H. 2005. Malezas exóticas comestibles y medicinales utilizadas en poblaciones del noroeste patagónico: Aspectos etnobotánicos y ecológicos. B. Latinoam. Caribe Pl., BLACPMA 4: 75-80

MARTÍNEZ, G. J. 2012. Actualidad y pasado del uso de plantas silvestres comestibles entre los tobas del Impenetrable chaqueño -Reflexiones, discursos y prácticas en torno a la alimentación. En BABOT, M. P., MARCHOF, M. \& F. PAZZARELLI (eds.), Las manos en la masa. Arqueología y antropologías de la alimentación en Suramérica. Actualidad Argentina, pp. 47-69. Universidad Nacional de Córdoba, Córdoba.

MARTÍNEZ, G. J. 2015. Cultural patterns of firewood use as a tool for conservation: a study of multiple perceptions in a semiarid region of Cordoba, Central Argentina. Journal of Arid Environment 121: 84-99.

MUIÑO, W. A. 2012a. Estudio etnobotánico de plantas usadas en la alimentación de los campesinos del Noroeste de La Pampa, Argentina. Chungara Rev. Antrop. Chil. 44: 389-400.

MUIÑO, W. A. 2012b. Los "puestos" del oeste pampeano. La relación de los campesinos criollos con las plantas a través de los huertos y jardines. En ARENAS, P. (ed.), Etnobotánica en zonas áridas y semiáridas del cono Sur de Sudamérica, pp. 225-249. CEFYBO, CONICET. Buenos Aires.

REMEDI, F. J. 1997. Las condiciones de vida material: Cocinas étnicas y consumo alimentario en la provincia de Córdoba a comienzos de siglo. En ALVAREZ, M. \& L. C. PINOTTI (eds.), Procesos socioculturales y alimentación, pp. 99-137. Ed. del Sol, Buenos Aires. 
ROSCH, E., C. B. MERVIS, W. D. GRAY, D. M. JOHNSON \& P. BOYES-BRAEM. 1976. Basic objects in natural categories. Cognitive Psychol. 8: 382-439.

SAUR PALMIERI, V., M. L. LÓPEZ \& C. TRILLO. 2018. Aproximaciones etnobotánicas de las especies y prácticas de frutos nativos comestibles de la actualidad. Aportes para la interpretación del pasado prehispánico de Cerro Colorado (Córdoba, Argentina). Bol. Soc. Argent. Bot. 53: 115-133.

SCARPA, G. F. 2009. Wild food plants used by the indigenous peoples of the South American Gran Chaco: A general synopsis and intercultural comparison. J. Appl. Bot. Food Qual 83: 90-101.

SCARPA, G. F. 2012. Las plantas en la vida de los criollos en el oeste formoseño: medicina, ganadería, alimentación y viviendas tradicionales. Ed. Rumbos Sur, Buenos Aires.

SCARPA, G. F. \& P. PACOR. 2017. ¿Por qué ya no recolectan los recolectores? Procesos de estigmatización del consumo de plantas silvestres entre los indígenas chorote del chaco salteño. Runa 38: 73-89.

STRAUSS, A. \& J. CORBIN. 1998. Basic of qualitative research: Techniques and procedures for developing grounded theory. Second ed. Sage Publ. Inc., London.

TOLEDO, J. M., A. CORREA \& G. BELTRAMONE. 2015. Frutos comestibles nativos de Córdoba, Argentina Ed. Advocatus, Córdoba.

TORRELLA, S. \& J. ADÁMOLI. 2005. Situación ambiental de la ecorregión del chaco seco. En BROWN, A., U. MARTÍNEZ ORTIZ, M. ACERBI \& J. CORCUERA (eds.), La Situación Ambiental Argentina, pp. 75-82. Fundación Vida Silvestre.

TRILlO, C., S. COLANTONIO \& L. GALETTO. 2014. Perceptions and use of native forests by residents of the arid Chaco region in Córdoba, Argentina. Ethnobot. Res. Appl. 12: 497-510.

TRILLO, C. 2016. Prácticas tradicionales de manejo de recursos vegetales en unidades de paisajes culturales del oeste de la provincia de Córdoba, Argentina. Zonas Áridas 16: 81-111.

Original recibido el 2 de octubre de 2017; aceptado el 20 de noviembre de 2018. 
Anexo 1. Alimentos y comidas mencionadas en las entrevistas.

Appendix 1. Food and meals mentioned in the interviews.

\begin{tabular}{|c|c|c|}
\hline $\begin{array}{l}\text { Alimentos con productos } \\
\text { animales }\end{array}$ & Alimentos con productos vegetales & \\
\hline Carnes asadas & $\begin{array}{l}\text { Alimentos con productos de la chacra } \\
\text { y huerta (maíz, zapallo y otros) }\end{array}$ & $\begin{array}{l}\text { Dulces, mermeladas, } \\
\text { arropes y confituras }\end{array}$ \\
\hline $\begin{array}{l}\text { Pecarí o chancho del monte } \\
\text { asada }\end{array}$ & $\begin{array}{l}\text { Mazamorra: Se hierve hasta ablandar el } \\
\text { maíz blanco del locro, se podía agregar } \\
\text { leche de vaca o de cabra. Antes se } \\
\text { consumía en lugar del mate cocido de } \\
\text { hoy }\end{array}$ & Arrope de chañar \\
\hline Corzuela & Locros & Arrope de algarroba \\
\hline Vaca asada con cuero & $\begin{array}{l}\text { Sopa de maíz: Se remojaba el maíz, se } \\
\text { hacía fuego y hervía, agregaba zapallo; } \\
\text { aparte se prepara una salsa con orégano } \\
\text { y pimentón }\end{array}$ & Arropes de tunillas \\
\hline Asado a la rastra & Sopa de trigo & Arrope de tuna \\
\hline Asado a la estaca & Batatas hervidas en hojas de higuera & Arrope de uva \\
\hline Asado en bolsa & Batata asada con leche & $\begin{array}{l}\text { Arrope de miel, con casco } \\
\text { de zapallo y sandía }\end{array}$ \\
\hline Cabrito & Batata en almíbar & Dulce de higos \\
\hline Lechón & $\begin{array}{l}\text { Choclín: Es un choclo rayado como un } \\
\text { locro, se cocinaba con cebolla, pimiento, } \\
\text { se ponía en fuente con verduras y } \\
\text { se lo llevaba a horno. Se servía con } \\
\text { espumadera pues era blando, y se } \\
\text { agregaba queso. }\end{array}$ & Dulce de moras \\
\hline $\begin{array}{l}\text { Chacinados, productos } \\
\text { cárnicos y achuras }\end{array}$ & Choclo asado & Dulce de níspero \\
\hline Charqui & Charqui de zapallo & Dulce de durazno \\
\hline $\begin{array}{l}\text { Jamón cocido de jabalí: Se } \\
\text { deshuesa la pierna y se sala por } \\
1 \text { día; luego se hierve y prensa } \\
\text { hasta que esté firme; se pone sal } \\
\text { de nitro para chacinados. }\end{array}$ & Humita con chala y a la olla & \\
\hline Arrollado de cerdo & Niños envueltos con chala & Dulce de uvas \\
\hline Matambre arrollado & Niños envueltos con repollo & Dulce de zarzamora \\
\hline Bondiola de cerdo & Niños envueltos con hoja de parra & Dulce de zapallo \\
\hline $\begin{array}{l}\text { Chorizo y salamines de pecarí o } \\
\text { chancho del monte }\end{array}$ & $\begin{array}{l}\text { Sanco de harina de maíz blanco diente } \\
\text { de caballo, se lo ponía en remojo, se } \\
\text { pelaba y se saltaba con cebolla }\end{array}$ & Dulce de membrillo \\
\hline $\begin{array}{l}\text { Salamín de corzuela (tiene sabor } \\
\text { del cabrito), se prepara con grasa } \\
\text { de cerdo. }\end{array}$ & Zapallo criollo asado & Dulce de naranja \\
\hline Salame de vizcacha & $\begin{array}{l}\text { Tortillas de lengua de vaca, achicoria del } \\
\text { campo }\end{array}$ & Dulce de lima \\
\hline $\begin{array}{l}\text { Sopas, caldos y potajes, } \\
\text { guisos, pucheros y estofados }\end{array}$ & Torrejas & $\begin{array}{l}\text { Compota de níspero, } \\
\text { duraznos }\end{array}$ \\
\hline Sopa de huevo & Achicoria del campo & $\begin{array}{l}\text { Pelones (duraznos } \\
\text { pelados y secados al sol) }\end{array}$ \\
\hline Puchero chico o sopa picada & Berro & Nueces confitadas \\
\hline Puchero & Cardo (antes de florecer) & \\
\hline Estofado de cabritos & Diente de león & $\begin{array}{l}\text { Desayunos, meriendas, } \\
\text { postres y colaciones }\end{array}$ \\
\hline
\end{tabular}




\begin{tabular}{|c|c|c|}
\hline $\begin{array}{l}\text { Sastaca, Sasta: Charqui molido } \\
\text { con cebolla, huevo condimentos } \\
\text { varios }\end{array}$ & Acacia blanca (flor) & Mote: maíz amarillo \\
\hline Buseca & Lengua de vaca & $\begin{array}{l}\text { Mazamorra con y sin } \\
\text { leche }\end{array}$ \\
\hline $\begin{array}{l}\text { Pecarí o chancho del monte } \\
\text { al disco con cebolla, pimiento, } \\
\text { tomate y vino }\end{array}$ & Panificados y harinas & Maicena con leche \\
\hline Pollo al disco & Pan cordero & Harina con leche \\
\hline $\begin{array}{l}\text { Preparados con animales del } \\
\text { río (peces, aves) }\end{array}$ & Pan con semita & $\begin{array}{l}\text { Polenta con leche (harina } \\
\text { de maíz con azúcar, } \\
\text { espesa) }\end{array}$ \\
\hline $\begin{array}{l}\text { Moncholo. Frito, en estofado o } \\
\text { empanada. Es una carne blanca, } \\
\text { sabrosa, con papas, cebollas, } \\
\text { pimientas. }\end{array}$ & Pan casero con grasa & Arroz con leche \\
\hline Macerados y escabeches & Pan con chicharrón & $\begin{array}{l}\text { Leche con menta o yerba } \\
\text { buena }\end{array}$ \\
\hline $\begin{array}{l}\text { Vinagre con la cáscara de los } \\
\text { duraznos }\end{array}$ & Pan casero sin grasa & Budín de pan \\
\hline Paloma en escabeche & Pan dulce con pasas y fruta abrillantada & Buñuelos \\
\hline $\begin{array}{l}\text { Liebre en escabeche (es una } \\
\text { carne muy negra pero sabrosa) }\end{array}$ & Tortilla o torta parrilla o tortilla al rescoldo & Pastelitos \\
\hline \multirow[t]{2}{*}{ Vizcacha en escabeche } & Tortas dulces & $\begin{array}{l}\text { Empanadilla de dulce de } \\
\text { batata }\end{array}$ \\
\hline & Tabletas & Bizcochuelos \\
\hline $\begin{array}{l}\text { Preparados con animales del } \\
\text { río (peces, aves) }\end{array}$ & & Pastaflora \\
\hline $\begin{array}{l}\text { Moncholo. Frito, en estofado o } \\
\text { empanada. Es una carne blanca, } \\
\text { sabrosa, con papas, cebollas, } \\
\text { pimientas. }\end{array}$ & Amasados & $\begin{array}{l}\text { Compotas, de durazno, } \\
\text { albarillo }\end{array}$ \\
\hline Comidas con carbonadas & Fideos verdes con acelga & Flan \\
\hline Empanadas & Fideos caseros con harina de maíz & Fritos con arrope de miel \\
\hline Pastel de carne y papa & Ñoquis con harina de maíz & Naranja con merengue \\
\hline Quesos & Carbonadas & Puré de batata \\
\hline Quesillo de hoja & Tamales & $\begin{array}{l}\text { Coctel (huevo con azúcar } \\
\text { y vino dulce batido) }\end{array}$ \\
\hline Quesillo de cabra & Pastel de carne y papa & \\
\hline Queso de vaca & Empanadas de vigilia & Bebidas \\
\hline \multirow[t]{5}{*}{ Quesillos } & & Alojas de algarroba \\
\hline & & Licor de peperina \\
\hline & & Licor de menta \\
\hline & & Licor de molle (fruto) \\
\hline & & Licor de mandarina \\
\hline
\end{tabular}


